\title{
A circulação de ideias sobre as interações fundamentais como a síntese embrionária do Modelo Padrão da Física de Partículas Elementares
}

\author{
The Fundamental Interactions Ideas Circulation as the \\ Embryo Synthesis of the Standard Model of Particle Physics
}

\author{
Renan Milnitsky \\ Doutorando do Programa de \\ Pós Graduação Interunidades \\ em Ensino de Ciências da \\ Universidade de São Paulo \\ renan.milnitsky@usp.br
}

Recebido em: 30/12/2019 Aceito em: 15/04/2020

\section{RESUMO}

Neste artigo serão apresentadas reflexões sobre como a circulação de ideias em diferentes momentos da história da Física de Partículas contribuíram para formar o embrião do Modelo Padrão da Física de Partículas Elementares. A narrativa histórica foi construída em três fases que tem como intuito apresentar um panorama geral da circulação de ideias e o ideal de "Modelo Padrão" que as guiou em cada um dos contextos. A Fase Atômica (1890-1932) se dedica a explicar a estrutura da matéria, suas formas de decaimentos e composição das diferentes formas de radiação. A Fase das Interações (1932-1947) descreve como as tentativas de construção de teorias quânticas para as interações fundamentais tentou acompanhar as novidades reveladas pela produção em larga escala de dados experimentais provindos das pesquisas em raios cósmicos. A Fase das Simetrias e Conservações (1947-1964) circunda a discussão sobre as partículas estranhas, na busca por princípios de simetrias e conservações. Ao final, discute-se como os primeiros mecanismos de quebra de simetria foram utilizados na formulação do quark e constituíram um prelúdio para o Modelo Padrão.

Palavras-chave: Física de Partículas, Modelo Padrão, História da Ciência, Epistemologia Histórica

\section{ABSTRACT}

This article will present reflections on how the circulation of ideas at different times in the history of particle physics contributed to forming the embryo of the Standard Model of Elementary Particle Physics. Historical development was organized into three phases that present an overview of the circulation of ideas and the "Standard Model" that guided each of them on each context. The Atomic Phase (1890-1932) is dedicated to explaining the structure of matter, its decay forms and the composition of the radiation forms that exist in it. The Interaction Phase (1932-1947) describes how the attempts to construct quantum theories for fundamental interactions attempted to keep up with the novelties revealed by the large scale data production provided by the cosmic ray researches. The Symmetry and Conservation Phase (1947-1964) surrounds the discussion of foreign particles in search of symmetry and conservation principles. In the end, we discuss how the first symmetry breaking mechanisms were used in the quark formulation and were a prelude to the Standard Model.

Keywords: Particle Physics, Standard Model, History of Science, Historical Epistemology 


\section{As fases de desenvolvimento do Modelo Padrão da Física de Partículas: a força do transnacionalismo}

O Modelo Padrão da Física de Partículas é, atualmente, a tentativa mais bem consolidada de explicação não só da estrutura da matéria, mas também de sua diversidade e das suas interações. Com a organização em Léptons, Quarks e Bósons de Gauge apresentadas na Figura 1, a comunidade de cientistas da chamada Física de Altas Energias tem tentado responder a questões fundamentais sobre as origens da matéria e da energia.

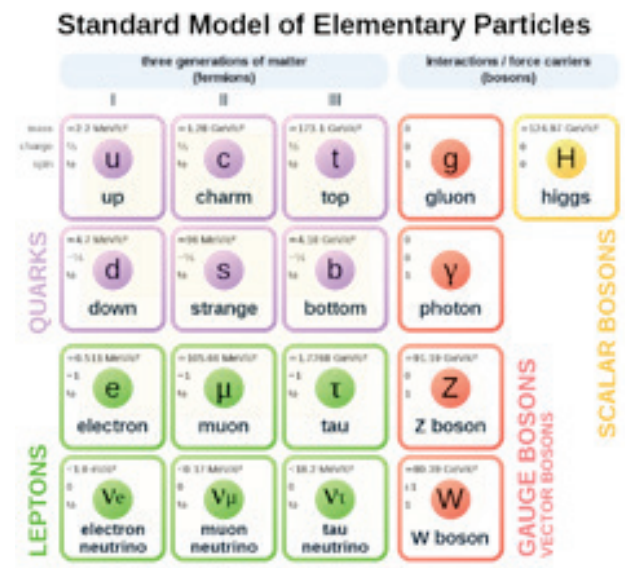

Figura 1 - O Modelo Padrão da Física de Partículas Elemementares. (Fonte: Wikipedia)

A icônica tabela contida na Figura 1 se tornou o símbolo não só da pesquisa, mas também da divulgação e do ensino da Física de Partículas. É preciso perceber, no entanto, que por trás dela se esconde uma história que traz consigo as marcas características de um fazer científico que foi se constituindo na Física ao longo de todo o século XX. A Física de Partículas nasce e é tomada por influências da revolução científica causada pela Mecânica Quântica e pela teoria da Relatividade. Ela é marcada por uma nova cultura teórica e experimental que tem inspirado uma série de filósofos, historiadores, sociólogos e físicos a realizar um trabalho de reconstrução de sua história. Essa diversidade de olhares pode ser percebida nas três obras de referência na reconstrução histórica da física de partículas The Birth of Particle Physics (1983), Pions to Quarks: Particle Physics in the 1950s (1989) e The Rise of the Standard Model: Particle Physics in the 1960s e 1970s (1997), editadas e organizadas pela historiadora da ciência Lillian Hoddeson, pelo físico teórico Laurie Brown e pelos físicos experimentais e historiadores da ciência Max Dresden e Michael Riordan.

Esse interesse peculiar na construção de uma memória da Física de Partículas se dá pela multiplicidade de olhares que ela oferece, o que reflete diretamente nas diferentes dimensões envolvidas em seu desenvolvimento. A junção de um novo panorama teórico a uma nova cultura experimental, aliada à consolidação da dinâmica científica de colaborações, só foi possível porque houve uma inclinação à facilidade de reprodução de resultados, em obras editadas com material de baixo custo, o que facilitou sua circulação em comunidades científicas de países com poucos recursos financeiros. Neste sentido, uma publicação que começou a circular nos anos 1960 para atender a esta preocupação foi a Frontiers in Physics, que cumpriu papel importante na colaboração entre físicos de diferentes países. ${ }^{1}$ Entre Hideki Yukawa no Japão e Carl Anderson nos Estados Unidos na busca pelos mésons, Shin’ichiro Tomonaga no Japão e Richard Feynman nos EUA na construção da Eletrodinâmica Quântica, Murray Gell-Mann nos EUA e Yuval Ne'eman em Israel na formulação do Quark, vemos o embrião do Modelo Padrão da Física de Partículas Elementares nascendo a partir da circulação de ideias e na diversidade de culturas de pensamento de diferentes localidades ao redor do mundo. Como estamos tratando de física teórica, os eventos internacionais nos quais os físicos divulgavam suas ideias e a circulação de artigos publicados cumpriram papel crucial para o desenvolvimento do modelo padrão.

1 O autor agradece aos pareceristas anônimos pela indicação desta publicação. 
A história da Física de Partículas é comumente escrita sobre a construção de narrativas que giram no entorno de evidências, descobertas ou formulações teóricas e experimentais de novas partículas. O Particle Data Group (PDG), em parceria com o Institute of High Energy Physics (IHEP), elaborou um acervo digital nomeado Chronology of Milestone Events in Particle Physics ${ }^{2}$ onde identificam principais eventos históricos que contribuíram para a evolução e desenvolvimento da Física de Partículas e os associam aos artigos publicados nos principais periódicos globais de cada uma das épocas. Fruto deste trabalho, linhas do tempo como a mostrada na Figura 2, passam a figurar nos campos de divulgação da Física de Partículas.

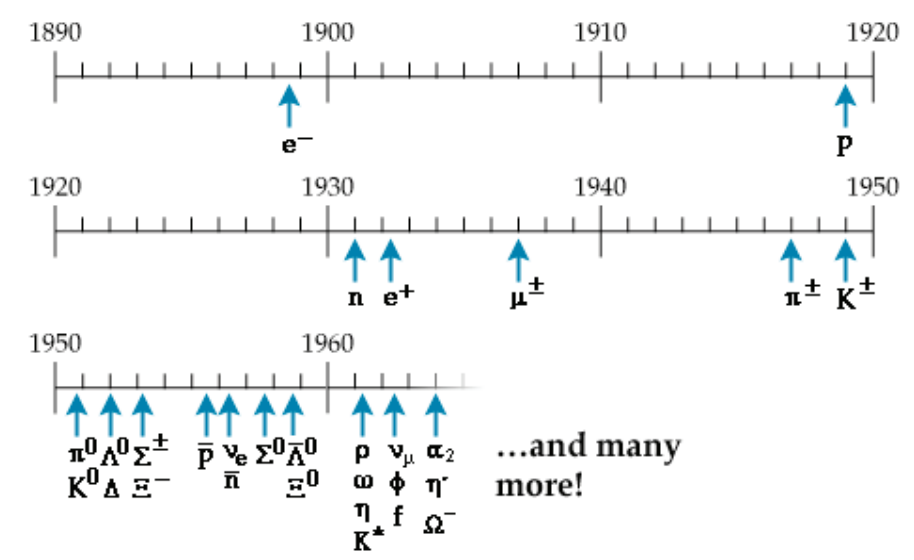

Figura 2 - Partículas descobertas no período 1898-1964. (Fonte: Particle Data Group.)

No entanto, somente um olhar histórico para os eventos que entremeiam as partículas identificadas nesta linha do tempo podem nos apresentar um olhar mais apurado sobre como este desenvolvimento aconteceu. Brown e Hoddeson (1983) propõe a existência de fases de desenvolvimento nas diferentes micro áreas que constituem a Física de Partículas, propondo na introdução da obra The Birth of Particle Physics, exemplificações delas na Física de Raios Cósmicos e das Teorias Quânticas de Campo. Organizamos fases de desenvolvimento que conduziram ao embrião do Modelo Padrão mobilizadas pela circulação de ideias sobre as interações fundamentais entre o começo do século XX e meados da década de 60. A organização temporal destas fases está apresentadas na Figura 3, construída tomando como base a Figura 2.

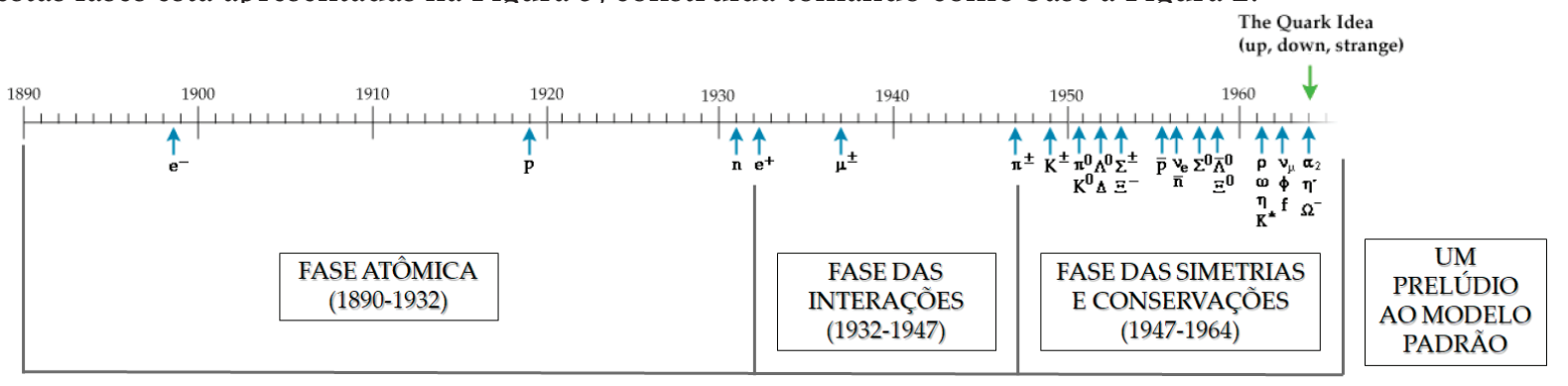

Figura 3 - Fases de Desenvolvimento e o embrião Modelo Padrão da Física de Partículas Elementares.

Fonte: Adaptado de Particle Data Group

\section{Fase Atômica (1890-1932)}

\section{II.1 Natureza e diversidade das radiações}

O famoso trabalho do cientista inglês Joseph Thomson em 1897, sobre descoberta dos elétrons, amplamente discutido nos textos de história da ciência e descrito em detalhe por George Smith (2001), remonta as

2 O acervo está disponível em <http://web.ihep.su/owa/dbserv/hw.part1> (Acesso em: 01/12/2019) 
evidências de uma radiação denominada pelo cientista inglês como catódica, que era emitida quando uma diferença de potencial de alto valor era aplicada sobre um filamento no interior do canônico tubo de raios catódicos. Roberto Martins (1998) reconstrói as evidências encontradas por Wilhelm Roetgen, na Alemanha, ao final de 1895, que ocorriam paralelamente aos trabalhos de Thomson. Nestas experiências, Roetgen revelou que o freamento de raios catódicos produziria uma radiação ainda não conhecida, denominada pelo cientista alemão como radiação X. Esta, diferentemente dos raios catódicos, não sofria deflexão sob a presença de campos elétricos e magnéticos. Segundo Martins (1990), a descoberta de Roetgen inspirou uma série de investigações na região da França.

Henri Becquerel, em 1896, tomando como base recentes trabalhos de Boleslas Niewenglowski, percebeu que havia outra radiação para além dos raios-X, que era emitida naturalmente por objetos como o Urânio. Ao contrário dos raios- $\mathrm{X}$, a radiação percebida por Becquerel seria de baixíssima penetrabilidade e suscetível (assim como os raios catódicos, mas com uma dificuldade imensamente maior) às deflexões de trajetória pela presença de campos elétricos e magnéticos. Estes raios ficaram à época conhecidos como raios Becquerel ou raios Urânio.

O reconhecimento da presença das radiações catódica, X e becquerel deram instrumentos para que físicos à época realizassem experiências cujos resultados eram fenômenos peculiares à época. Um deles chamou a atenção da até então estudante francesa Marie Curie, que buscava um projeto para seu doutoramento. $\mathrm{O}$ denominado problema da ionização residual do ar era percebido nos gases que se encontravam no interior dos tubos de raios catódicos. A exposição destes gases às radiações conhecidas na época provocava no gás o aparecimento de pequenas diferenças de potencial, que podiam ser detectadas com eletroscópios. Curie e outros cientistas aventaram a hipótese de que a origem desta ionização estava em outros materiais disponíveis na natureza, que, assim como o Urânio, ao emitir naturalmente radiação, seriam os principais responsáveis pela ocorrência do fenômeno observado. Curie e seu marido identificaram novos elementos radioativos, como o Rádio, e perceberam a existência de três tipos de radiação emitidas naturalmente por estes elementos, que possuíam diferentes penetrabilidades e suscetibilidades a campos elétricos e magnéticos. Foi Ernest Rutherford, em 1903, na Inglaterra, que classificou estas três radiações como: radiação a, eletrizada positivamente, de fácil absorção e responsável por grande parte da ionização residual percebida nos tubos de raios catódicos; radiação $\beta$, eletrizada negativamente e de natureza bastante semelhante à dos raios catódicos estudados por Thomson; radiação $\gamma$, bastante semelhante aos raios-X, mas com maior capacidade de penetrabilidade e não suscetível a desvios pela presença de campos elétricos e magnéticos.

Apesar das descobertas de novos elementos radioativos e da classificação mais precisa das radiações emitidas por eles, Martha Bustamante (2013) aponta que investigações realizadas pelo físico italiano Domenico Pancini, ao longo da primeira década do século XX, demonstraram que as radiações emitidas pelos novos elementos não provocavam a ionização no ar. $\mathrm{O}$ que se considerou à época era que a ionização residual do ar atmosférico era provocada por uma radiação que provinha de fora da Terra. Esta hipótese foi sustentada pelos resultados de experimentos conduzidos pelos físicos austríacos Victor Hess e Albert Godel, de que a ionização se torna mais significativa em altitudes elevadas, uma vez que não era possível detectar a esperada diminuição na intensidade desta misteriosa radiação em relação à altitude. Esta fonte de radiação penetrante é denominada por Hess como radiação Cósmica. (HESS, 1913).

Como bem aponta Augusto Fitas (1996), em sua análise sobre as influências da filosofia de Mach ao final do século XIX, a doutrina positivista, em busca de um princípio de minimalismo teórico, negava a construção de teorias baseadas em entidades inobserváveis, elegendo como uma de suas principais oponentes as teses atomistas, uma vez que elas constituem "uma teoria física muito complicada; um átomo nunca se observara, era impossível a sua comprovação experimental, logo esta teoria não teria sentido." (Fitas, 1996, p.8). É neste contexto que Peter Galison defende que a invenção da câmara de nuvens pelo físico e meteorologista britânico Charles Wilson, além de causar uma revolução na física experimental do século XX, acaba por se constituir como uma verdadeira conciliadora dos conflitos com as concepções antiatomistas da época (GALISON, 1997). 
Entre a primeira e a segunda década do século XX, as câmaras de nuvem, junto com contadores Geiger, estimularam a produção de traços tanto de decaimentos radioativos, levantando graves problemas teóricos associados aos comportamentos obtidos no decaimento $\beta$, quanto do estudo de raios cósmicos, cuja alta penetrabilidade levou os físicos a pensarem, erradamente, que sua composição era de radiação $\gamma$. Em 1929, Pierre Auger \& Dmitri Skobeltzyn fizeram análises do espectro de raios $\gamma$ provindos da radiação cósmica, e detectam nas câmaras de nuvem trajetórias de partículas sendo defletidas pela ação de campos magnéticos (Auger 1983; e Skobeltzyn 1983). No mesmo ano, na Alemanha, Bothe e Kolhorster também realizam a detecção de partículas de menor penetrabilidade utilizando folhas de ouro de $4 \mathrm{~cm}$ de espessura colocada entre dois contadores Geigers - a detecção no primeiro contador e a não detecção no segundo, sugeria a absorção das partículas pela folha de ouro, o que não ocorria com a radiação $\gamma$. Estes trabalhos são considerados um marco na Física de Raios Cósmicos, por demonstrarem que sua natureza material é constituída essencialmente por elétrons. Sob influência destes trabalhos, Carl Anderson passou a se dedicar ao estudo destas propriedades materiais dos raios cósmicos.

Os primeiros estudos apontavam para energias incidentes da ordem de 15 milhões de elétron-volts $(\mathrm{MeV})$, sendo que as maiores medidas indicavam 5 bilhões de elétron-volt $(\mathrm{GeV})$. Os resultados preliminares mais curiosos consistiram na verificação de ionizações pontuais provocadas pela incidência de radiação eletromagnética, sendo que grande parte das trajetórias identificadas era de partículas eletrizadas com uma unidade de carga positiva (+e) e negativa (-e). Segundo Anderson, "as partículas de carga negativa foram prontamente interpretadas como elétrons, enquanto que as dotadas de carga positiva foram, num primeiro momento, identificadas como prótons, a única partícula conhecida contendo uma unidade de carga positiva." (ANDERSON, 1936, p.365, tradução nossa). Apesar da similaridade na unidade de carga elétrica, os comportamentos contradiziam tudo o que se podia esperar de prótons: tanto as ionizações provocadas ao passar pela câmara de nuvem quanto os raios das curvaturas percebidos pela presença de campos magnéticos eram semelhantes ao de um elétron, de modo que "a única conclusão possível era de que esta trajetória, de fato, era a trajetória de um elétron carregado positivamente. (ANDERSON, 1936, p. 366, tradução nossa). Este é o marco da primeira evidência histórica da existência de antimatéria, levando na época o cientista estadunidense a denominá-la como pósitron. Paralelamente, sem tomar conhecimento dos trabalhos de Anderson, Paul Dirac (1928), na tentativa de formular uma versão relativística da teoria quântica do elétron, prevê teoricamente a possibilidade de elétrons carregados positivamente.

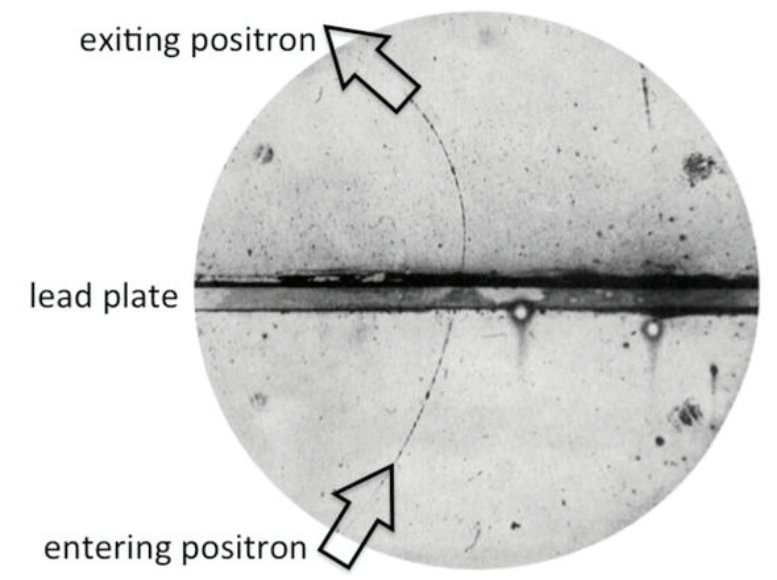

Figura 4 - Trajetória do pósitron analisada por Anderson em uma câmara de nuvem. A diminuição no raio de curvatura da trajetória é possibilitada pela interação da partícula com a placa de chumbo. Fonte: Anderson, 1933 


\section{II.2 A Estrutura atômica da matéria}

A descoberta do elétron, assim como a investigação do espectro de radiação descontínuo emitido por uma série de elementos estudados na época, influenciou na consolidação de uma corrente de estudo sobre a estrutura da matéria, paralela e complementar ao estudo das radiações. A reconstrução histórica de determinados momentos deste período já foi exaustivamente discutida na literatura. No entanto, no que concerne à circulação de ideias e à gênese de conjecturas que influenciaram a construção do Modelo Padrão, existem pontos que precisam ser destacados. Apesar de as atividades de formulação teórica de modelização dos átomos estarem concentradas na Europa, físicos japoneses operaram contribuições importantes para o alcance da maturidade da Física de Partículas.

Mitsuo Taketani, destaca dois momentos de fundamental importância para a escola de pensamento japonesa: os trabalhos de Hantaro Nagaoka em 1903 e de Jun Ishihara em 1915, que realizam movimentos epistemológicos semelhantes aos percebidos pelos trabalhos de Thomson, Rutherford e Bohr na Europa. Segundo Eri Yagi (1972) e Charles Baily (2008), a proposição de Nagaoka (1903) surge no ano anterior à de Thomson (1904) com diferenças qualitativas significativas em termos da proposição da estrutura atômica, mas com semelhanças nas conjecturas teóricas utilizadas para explicar fenômenos observados empiricamente. $\mathrm{O}$ modelo composto por Nagaoka consistia de uma analogia ao sistema saturniano de anéis, sendo composto por "um determinado número de elétrons negativos de mesma massa, distribuídos de forma uniforme em um anel circular e uma esfera positivamente carregada de grande massa, localizado no centro deste anel." (YAGI, 1972, p.73, tradução nossa). Já no famoso modelo proposto por Thomson, os elétrons se encontravam distribuídos em anéis concêntricos, encontrados no interior de uma esfera positivamente carregada. Em ambos os sistemas o átomo é considerado eletricamente neutro, com elétrons realizando movimentos orbitais no entorno da carga positiva, no caso de Nagaoka, ou no interior da esfera positivamente carregada, no caso de Thomson. Do ponto de vista de resolução teórica, Thomson busca condições para a estabilidade das órbitas usando a teoria eletromagnética aliada a mecânica newtoniana, perseguindo um equilíbrio dinâmico das forças elétricas. Já Nagaoka, preocupado em não depender da origem de coordenadas, busca estabilidades utilizando o formalismo lagrangeano. (YAGI, 1972; BAILY, 2008).

Bastante estimulado pelas reflexões teóricas de Thomson, Rutherford conduz, junto com os físicos Hans Geiger e Ernest Marsden, os experimentos de incidência de partículas a em alvos contendo materiais de diferentes composições atômicas, conhecido pela utilização das folhas de ouro. Os surpreendentes resultados de recuos de partículas a, não esperado por nenhum dos envolvidos, fez com que, em seu artigo de 1911, Rutherford mencionasse as limitações do modelo proposto por Thomson, ao mesmo tempo que tecia considerações sobre o modelo saturniano de Nagaoka, afirmando que "as chances de largas deflexões permanecem praticamente inalteradas, seja o átomo considerado como um disco ou uma esfera” (RUTHERFORD, 1911, p.42, tradução nossa). Com o intuito de explicar os grandes ângulos de espalhamento, Rutherford formula a famosa proposição de que o átomo consiste de "um núcleo de carga positiva de pequenas dimensões onde praticamente toda a massa do átomo estaria concentrada" (RUTHERFORD, 1913, p.488, tradução nossa) e em seguida aponta diversos problemas decorrentes desta proposição, ressaltando que "Bohr chamou a atenção para as dificuldades de se construir átomos na teoria 'nuclear' e demonstrou que as posições de estabilidade dos elétrons não poderiam ser deduzidas pela mecânica clássica.” (Ibid, 1913, p.499, tradução nossa).

A evidência do núcleo atômico eletrizado positivamente trouxe a descoberta dos prótons, concomitantemente aos problemas de estabilidade orbital que escancararam os limites da Física Clássica. É bastante comum, nas narrativas históricas da teoria atômica, redirecionar as reflexões de Rutherford diretamente a Niels Bohr, uma vez que o próprio cientista neozelandês o faz em seu artigo de 1913. Taketani (1982), no entanto, chama a atenção para o fato de que Ishiwara propõe condições de quantização em coordenadas generalizadas em seu artigo de 1915, intitulado como The Universal Meaning of the quantum of action. Taketani afirma que Ishiwara, junto com Nagaoka, formaram uma base que inspirou os grandes nomes da física teórica japonesa que ascenderiam nas próximas décadas e exerceriam papel fundamental na construção de teorias quânticas para as interações fundamentais da natureza. 


\section{II.3 Os mistérios envolvendo o decaimento}

Ainda que este conjunto de resultados contribuísse para o entendimento dos fenômenos observados, outros problemas associados começaram a ser manifestados. Geiger e Marsden perceberam que o espalhamento de partículas a começava a desviar do modelo nuclear de Rutherford a partir de determinadas energias, o que indicava que o núcleo, ao contrário do que se pensava, tinham uma estrutura e não era pontual. Além do mais, o decaimento $\beta$ apresentava comportamentos bastante peculiares, começando por uma mudança espontânea do número atômico do elemento, seguida da emissão de partículas eletrizadas negativamente com propriedades semelhantes a dos elétrons.

Joan Bromberg (1971), aponta que cientistas consideravam a ideia de que a presença de elétrons no decaimento $\beta$ estaria associada à sua presença no núcleo atômico. Assim, devido a instabilidades nucleares, o elétron seria forçosamente emitido. Heisenberg não assumia esta ideia, uma vez que, segundo o princípio da incerteza, os efeitos radiativos aliados a efeitos relativísticos exigiriam uma energia cinética que impediria uma órbita estável no interior do núcleo, mesmo se considerados os princípios de quantização. O problema se torna mais estranho quando se comparam os espectros de energia das radiações emitidas nos decaimentos a e $\beta$. Como o núcleo atômico era considerado muito pesado, era esperado que em decaimentos provocados pelas radiações $\alpha$ e $\beta$, fosse obtido um espectro discreto de energia, uma vez que toda a energia seria fornecida para a partícula ejetada, com o núcleo permanecendo estático devido a sua massa e suas dimensões. Era exatamente isto que acontecia com o decaimento $\alpha$, o que possibilitou as realizações experimentais de Rutherford com controle dos feixes e das energias no momento das colisões. No entanto, o espectro de emissão de elétrons no decaimento $\beta$ apresentava um espectro amplo, consideravelmente contínuo, indicando que ele poderia ser emitido com uma imensa diversidade de energias. Esse fenômeno era estranho, uma vez que, para que houvesse um espectro amplo de energias, ela deveria estar sendo distribuída para outro lugar, a não ser que o princípio de conservação de energia pudesse ser violado.

A resolução deste mistério vem sobre uma via de mão dupla, tendo como protagonistas, de um lado, Wolfgang Pauli, e de outro, James Chadwick. Em uma carta que ficou bastante famosa, Pauli (1929) sugere a existência de uma partícula neutra com uma massa excessivamente pequena, emitida conjuntamente com o elétron nos decaimentos $\beta$, para que o princípio de conservação da energia não fosse abandonado. Esta ideia foi desenvolvida por Fermi nas primeiras teorias sobre as interações fracas, que nomeou esta partícula como neutrino. Paralelamente, Chadwick (1932) anuncia a existência de partículas neutras emitidas nas capturas de partículas a em amostras de Berílio. No entanto, ao contrário do que sugeria Pauli, a partícula de Chadwick tem massa significativa, semelhante à massa do próton, denominada por ele como nêutron. Menos de três meses após ter ciência dos resultados de Chadwick, Werner Heisenberg (1932) articula explicações sobre a estrutura do núcleo atômico como composto por prótons e nêutrons e, mais adiante, desenvolveria a ideia de que prótons e nêutrons são diferentes estados de uma mesma partícula: o núcleon.

\section{Fase das Interações (1932-1947)}

\section{III.I A busca por uma teoria quântica para as interações fundamentais}

Os primeiros passos da Teoria Quântica de Campos (TQC) foram dados por Dirac $(1927,1928)$ ao tentar construir um formalismo que era relativístico e considerava o elétron acoplado a um campo eletromagnético - o que fica bastante claro na proposição de um hamiltoniano inicialmente composto por duas partes: uma para o átomo e outro para o campo eletromagnético. O principal objetivo de Dirac era avaliar a evolução temporal do hamiltoniano devido a perturbações externas. (WEISSKOPF, 1983; WEINBERG, 1977). Segundo Andrew Pickering (1984), o projeto de quantização da teoria eletromagnética, denominada como Eletrodinâmica Quântica (QED), passou a se constituir tradicionalmente em um programa de pesquisa que ficou conhecido como programa perturbativo ou lagrangeano, cujo objetivo era escrever a lagrangeana de um sistema em interação e, a partir dela, deduzir todas as propriedades de sua dinâmica. 
A construção da lagrangeana, no entanto, deveria satisfazer determinadas condições de contorno exigidas pela teoria quântica como, por exemplo, a quantização da interação e a ausência de massa no quantum da interação eletromagnética, uma vez que a interação eletromagnética tinha alcance macroscópico, que a nível quântico, é considerado como infinito. Qualitativamente, os termos mais importantes da lagrangeana, que representa a interação entre dois elétrons, estão apresentados na Equação 1:

$$
\mathcal{L}=\bar{\psi} D \psi+m \bar{\psi} \psi+(D A)^{2}+e A \bar{\psi} \psi \quad \text { Equação } 1
$$

Nesta equação, $\psi=\psi(x)$ representa a função de onda de cada um dos elétrons em interação; $A=A(x)$ a função que representa a quantização do campo eletromagnético, ou seja, o fóton; $\widehat{D}$ um operador que provoca evolução espaço-temporal, ou seja, representa as entidades em movimento, enquanto que "m" e "e" são constantes que representam, respectivamente, a massa e a carga do elétron. (PICKERING, 1984).

Segundo David Kaiser (2005), preocupado com a visualização e o significado físico dos componentes da equação, Feynman constrói uma representação imagética da lagrangeana em um método conhecido como Diagrama de Feynman, expostos na Figura 5. Cada termo da equação é dotado de um significado físico que tem, atrelado a ele, uma representação ilustrativa que exerce papel fundamental no diagrama. A função de onda $\psi$ representa um elétron em repouso e sem massa, por este motivo, os dois primeiros termos estão associados a sua materialização e movimentação. O primeiro, $\bar{\psi} D \psi$, representa um elétron em movimento devido à aplicação do operador $\mathrm{D}$ à função de onda $\psi$, enquanto que o segundo, $m \bar{\psi} \psi$, é inserido para dotar o elétron de massa "m". O terceiro termo $(D A)^{2}$ representa um fóton em movimento devido à aplicação do operador $\mathrm{D}$ à função $A=A(x)$. É importante notar a ausência de um possível termo $m A^{2}$, uma vez que a condição de contorno da interação eletromagnética define que o fóton, ao contrário do elétron, não deve ser dotado de massa. Por fim, o termo $e A \bar{\psi} \psi$, acopla o elétron $\psi$ ao fóton $A$, criando um vértice de interação elétron-fóton que tem intensidade proporcional à carga elementar "e", que é entendido como o mecanismo teórico fundamental para a explicação da quantização da interação eletromagnética.

\begin{tabular}{|c|c|}
\hline Elemento & Função matemática \\
\hline$\frac{\mathrm{e}^{-}}{\mathbf{e}_{\bar{\psi} D \psi}^{\text {Electron propagator }}}$ & $\begin{array}{l}\text { Dotar o elétron de massa e } \\
\text { representar sua evolução espaço- } \\
\text { temporal. }\end{array}$ \\
\hline$\overbrace{(D A)^{2}}^{\text {Photon propagator }}$ & $\begin{array}{l}\text { Representar a evolução espaço- } \\
\text { temporal da quantização do } \\
\text { campo eletromagnético: o fóton. }\end{array}$ \\
\hline$\underbrace{\text { Electron-photon vertex }}_{e A \psi \bar{\psi}}$ & $\begin{array}{l}\text { Representar vértice elétron-fóton, } \\
\text { percebido como elemento } \\
\text { fundamental para a quantização } \\
\text { das interações eletromagnéticas. }\end{array}$ \\
\hline
\end{tabular}

Figura 5 - Elementos constituintes da lagrangeana da QED e suas respectivas representações imagéticas nos Diagramas de Feynman. (Fonte: Própria. 2019) 
Tomando a equação completa, é possível descrever a interação entre dois elétrons mediada por um fóton que carrega a energia da interação, esquematizado no diagrama representado à esquerda da Figura 6 . No diagrama é possível perceber a existência de dois vértices de interação, como cada vértice contribui com uma magnitude "e", a interação, nesta primeira aproximação, é proporcional a e², assim como é deduzido na famosa Lei de Coulomb.
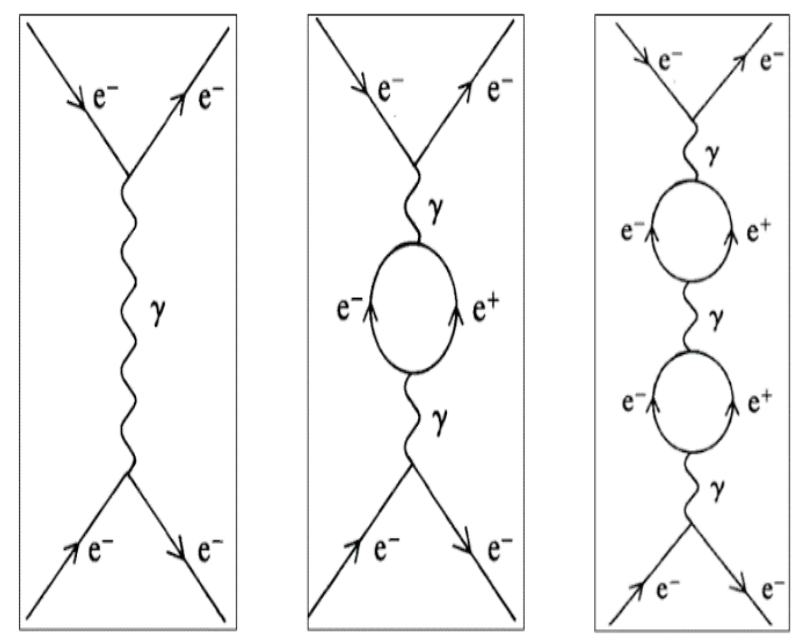

Figura 6 - Diagramas de Feynman representando a interação entre dois elétrons. Fonte: Pickering 1984

No entanto, a indeterminação da trajetória ocasionada na Física Quântica, assim como sua natureza probabilística, nos obriga a considerar infinitas outras possibilidades de mediação para o fóton na interação entre dois elétrons. No diagrama posicionado à direita da Figura 6 , o fóton que é emitido em um dos vértices produz um par elétron-pósitron, que se aniquila formando outros dois vértices de um segundo fóton que encerra a interação. Cada aproximação representa uma perturbação e é por este motivo que este método é conhecido também como perturbativo. É neste processo que aparecem dois principais problemas da QED, classificados por Pickering (1984) e Steven Weinberg (1977) como a doença dos infinitos, uma vez que os sintomas apresentados por eles serão transmitidos para as teorias das interações fortes e fracas.

O primeiro problema reside no fato de que existem infinitas possibilidades de perturbações e, em tese, todas elas deveriam ser consideradas. Para o eletromagnetismo este problema pode ser contornado graças às contribuições de Dirac, quando demonstrou que a constante de acoplamento eletromagnética, associada à magnitude da interação, representa um número menor que 1, mais especificamente, 1/137. Em consequência disto, o fato das perturbações mais complexas contribuírem com potências cada vez maiores da magnitude "e", demonstra que elas se tornam pouco significativas e os cálculos podem ser realizados concentrando-se apenas nas primeiras aproximações. O segundo problema reside no fato de que, mesmo considerando apenas as primeiras aproximações, ao tentar distribuir a energia do processo ao longo dos loops, os cálculos demonstravam que as integrais divergiam para o infinito. (PICKERING, 1984; WEINBERG, 1977). Apesar de diversos registros indicarem que estes problemas foram enfrentados por Richard Feynman, Julian Schwinger e Shin'ichiro Tomonaga; Silvan Schweber (1994) e Satio Hayakawa (1983) descrevem o verdadeiro esforço coletivo exigido por uma série de grupos de teóricos menos citados trabalhando tanto nos Estados Unidos, quanto no Japão.

Paralelamente às tentativas de construção de teorias quânticas eletromagnéticas, os problemas envolvendo o decaimento $\beta$ e a misteriosa constituição de um núcleo atômico não repulsivo, apesar de carregado positivamente, estimularam Hideki Yukawa a formular os primeiros passos na construção de teorias explicativas para as interações fortes. Takehiko Takabayashi (1983) afirma que em seus primeiros trabalhos, o físico japonês tenta estabelecer uma analogia com o fóton como o quantum da interação eletromagnética, para descrever a 
interação nuclear intermediada por elétrons, numa tentativa malsucedida de conciliar o decaimento $\beta$ com a estrutura do núcleo atômico. Em 1935, utilizando uma abordagem semiclássica de resolução do problema, Yukawa propõe um potencial de interação cujo alcance era limitado às dimensões experimentais de núcleos atômicos disponíveis à época. Para explicar a interação, a linha epistemológica japonesa sugere que seria intermediada por uma partícula de propriedades desconhecidas. Segundo suas deduções, ela deveria ter massa de aproximadamente $200 \mathrm{MeV}$.

Com uma partícula mediadora proposta, Pickering (1984) aponta que diversos teóricos tentaram adequar as hipóteses das interações fortes ao programa lagrangeano, construindo formalismos baseados em diagramas que se assemelham ao mostrado na Figura 7.

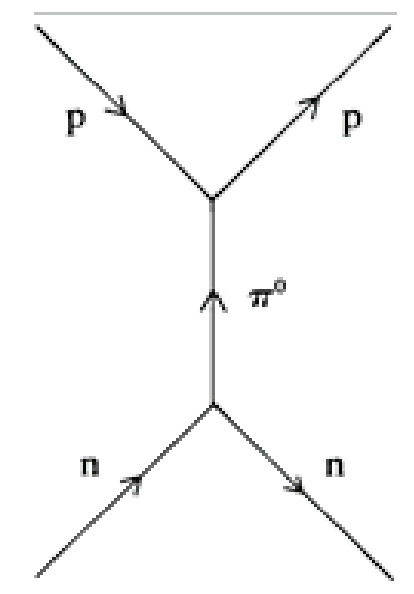

Figura 7 - Interação entre prótons e neutrons, constituintes dos núcleos atômicos, medidas por mésons como o proposta por Yukawa. Fonte: Pickering, 1984

Rapidamente, uma série de problemas começou a aparecer nesta tentativa. Todos associados às problemáticas condições de contorno que se estabelecem em uma teoria quântica para as interações fortes. As forças nucleares deveriam ser mediadas por uma interação de constante de acoplamento consideravelmente elevada para que os núcleos atômicos pudessem ser mantidos estáveis e coesos. Enquanto na interação eletromagnética a baixa constante de acoplamento sugeria que as perturbações de maior ordem teriam menor relevância, nas interações fortes este quadro se inverte. As aproximações mais relevantes seriam aquelas de maior ordem e, portanto, de maior complexidade. Além do mais, os infinitos apareciam com mais frequência, mesmo em perturbações de ordens menores. Em reflexões sobre os problemas que enfrentou em suas experiências com o programa lagrangeano nas interações fortes, Murray Gell-Mann (1996) relembra ter feito "aproximações ignorando os 'loops fechados' que originavam interações méson-méson" (Ibid., p.2) e de ter conseguido "escrever um novo tipo de equação relativística para o sistema nucleon-píon que deveria ser válida para todas as forças de acoplamento." (Ibid., p.2). No entanto, a experiência não foi muito frutífera, uma vez que relata nunca ter encontrado uma solução "para tal método do acoplamento forte. Na longa jornada, isto não importava mais, uma vez que ficou claro que nucleons e píons são na verdade compostos por quarks e gluons." (Ibid., p.2).

Os primeiros e significativos passos dados em direção à construção de uma teoria para as interações fracas foram dados por Enrico Fermi, após a reticente proposta de Pauli sobre a existência de neutrinos. Em 1934, Fermi publica um artigo onde apresenta as três premissas básicas de sua teoria. Ele tenta estabelecer uma analogia inspirada na emissão de fótons em processos de excitação atômica, de modo que sua primeira suposição é a de que elétrons e neutrinos são aniquilados ou criados no início ou no fim dos processos de decaimento $\beta$. A segunda suposição é a crença na hipótese de Heisenberg de que prótons e nêutrons representam dois estados quânticos distintos de uma mesma partícula. A terceira suposição é a de que, para que 
haja conservação de carga elétrica, a transição de um nêutron para um próton deve ser seguida da emissão de um elétron e um neutrino, enquanto que a transição inversa, de um próton para um nêutron, deve ser realizada sob aniquilação. (WILSON, 1968)

Alguns pontos dificultaram a descrição da teoria de Fermi em termos do programa lagrangeano. O primeiro deles está associado ao fato de que, para Fermi, o decaimento ocorria de forma pontual, obrigando que o alcance da interação fraca fosse nulo. Seguindo os raciocínios que foram utilizados na interação eletromagnética e forte, o que decorre desta proposta é uma condição de contorno para a construção de uma teoria quântica das interações fracas, onde a partícula mediadora deveria ter massa infinita para justificar seu alcance nulo. Assim, os diagramas de Feynman representando as interações fracas deveriam ter as características da Figura 8, onde o vértice de interação coincide com o próprio ponto onde ela ocorre, não necessitando de uma partícula mediadora.

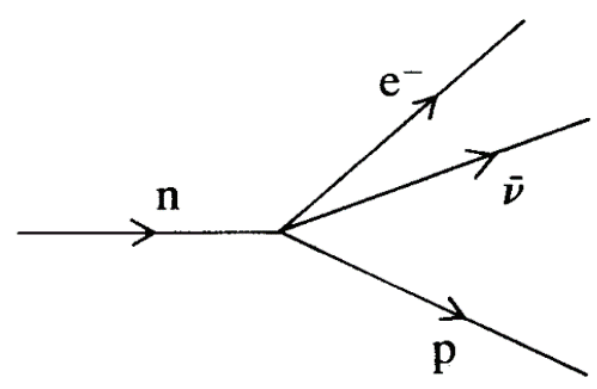

Figura 8 - Diagrama de Feynman representado o decaimento beta, onde um neutron sofre transição para o estado de um próton, seguido da criação de um par elétron-neutrino. Fonte: Pickering, 1984

Se não há partículas mediadoras, o que rege a interação fraca? Segundo Fortes, Tijero e Pleitez (2007), “a teoria de Fermi do decaimento $\beta$ [...] assumia que as interações fracas eram produzidas apenas por correntes carregadas, ou seja, induziam processos onde existia uma mudança na carga elétrica." (Ibid, p.418). As tais correntes carregadas, denominadas à época como correntes fracas, eram os elementos por meio dos quais as interações fracas eram descritas. No caso da Figura 8, a corrente n-p seria responsável pela criação da corrente e- $v$. Na Fase das Interações, os esforços dedicados à construção de teorias quânticas das interações fundamentais fizeram emergir uma série de novos formalismos e concepções associadas aos processos envolvendo partículas elementares. No entanto, como pode-se perceber, nenhuma destas teorias se consolida profundamente. A QED tem um relativo sucesso após propostas de renormalização ao final da década de 1940. Mas, a teoria de mésons das interações fortes, inicialmente proposta por Yukawa, e a teoria de Fermi, para o decaimento $\beta$, apresentavam uma série de lacunas que precisaram ser avaliadas cuidadosamente antes que pudessem ser satisfatoriamente solucionadas.

\section{III.2 A composição dos Raios Cósmicos e o paradoko nos decaimentos}

A busca pela real composição dos raios cósmicos acompanhou e moldou toda empreitada na busca por teorias quânticas para as interações fundamentais. Após as evidências experimentais da existência do pósitron nos raios cósmicos, passou-se a se questionar qual seria sua real constituição e como ela se comportaria nas diferentes regiões da atmosfera terrestre. Com este movimento, raios cósmicos passaram a ser estudados em diferentes lugares do mundo, produzindo uma imensa quantidade de dados que fomentou a discussão teórica pelas próximas duas décadas.

Imediatamente após o anúncio da descoberta do pósitron, as primeiras hipóteses sobre a produção de pares a partir da incidência de radiação $\gamma$ são postuladas por Yoshio Nishina e Tomonaga (1933), que, junto 
com Schoichi Sakata, em 1934, publicam os primeiros cálculos da seção de choque de produção deste tipo de reação, naquele que é considerado o "primeiro artigo da escola teórica de partículas elementares japonesa que recebe reconhecimento internacional." (Taketani, 1982, p.286, tradução nossa). Na comunidade japonesa, já se considerava a possibilidade da existência de novas partículas constituindo os raios cósmicos, alimentadas principalmente pelo desenvolvimento da teoria de mésons de Yukawa.

Paralelamente aos desenvolvimentos teóricos no Japão, Carl Anderson e Seth Neddermayer estavam interessados em estudar a natureza de um conjunto de radiações altamente penetrantes identificadas após a descoberta do pósitron. A principal evidência de pósitrons e elétrons na constituição dos raios cósmicos consistia na baixa penetrabilidade e suscetibilidade a desvios causados pela ação de campos magnéticos. Essa nova radiação, ao contrário das anteriores, além de ser altamente penetrante, era também suscetível à ação magnética. A postura pragmática e objetiva do pensamento ocidental buscou rapidamente uma racionalização desta nova radiação em termos de prótons e elétrons de altas energias - assumir a existência de novas partículas sem necessidade não fazia parte desta cultura científica. No entanto, a tentativa de compreensão destes fenômenos a partir de partículas já conhecidas encontrava pouquíssimo respaldo nas teorias que existiam até então.

Ao rememorar os trabalhos que realizou à época, Anderson (1982) relata que diversos problemas separavam prótons e elétrons da constituição desta radiação misteriosa. Apontava-se que elétrons de alta energia deveriam naturalmente sofrer freamentos devido a efeitos radiativos, o que era incompatível com o que havia sido detectado até aquele momento. Já com prótons, acreditava-se que, tanto a quantidade de ionizações provocadas nas câmaras de nuvem, quanto o espectro de partículas emitidas em chuveiros, produzidos em decorrência de suas colisões, deveriam ser muito mais extensos do que aqueles que se observavam experimentalmente. Neddermayer e Anderson relatam, em seu artigo de 1937, a estranha sensação de que este componente dos raios cósmicos aparentava ser mais pesado do que elétrons, ao mesmo tempo em que mais leve do que prótons, sugerindo, com reticências, a existência de uma nova partícula com massa intermediária entre as duas conhecidas.

Logo em seguida, Street \& Stevenson (1937) conduzem experimentos para mensurar a massa desta partícula, apontando em valores cerca de 130 vezes maior do que o do elétron, indicando que não poderia se tratar da famosa partícula carregada negativamente. Neste mesmo artigo, comparam as curvaturas realizadas por prótons e pelas novas partículas, ambas sob ação de um campo magnético. A perceptível diferença de curvatura aliada à nitidez da trajetória provocada pelo maior número de ionizações nas câmaras de nuvem são aspectos que demonstram sua superioridade de massa e descarta a sua composição por prótons, como pensado por Anderson e Neddermayer.

A notícia do mésotron, ou muon $(\mu)$ como ficou conhecido atualmente, detectado em duas versões, positiva e negativa, foi recebida com muitas comemorações pela comunidade japonesa, uma vez que havia sido realizada de forma paralela e independente à proposição de Yukawa. As reações mais naturais buscaram associar a partícula evidenciada pelo grupo experimental como o méson da teoria prevista por Yukawa. No entanto, a diferença entre a massa deduzida pelo físico teórico japonês e a medida feita pelo grupo de físicos experimentais estadunidenses apontavam para resultados significativamente diferentes. Além do mais, a exigência crucial para se candidatar como o méson previsto por Yukawa, era a de que ela interagisse fortemente com a matéria, podendo ser rapidamente absorvida por núcleos atômicos. Tomonaga e Gentaro Araki (1940) publicaram um estudo apontando que, como o núcleo é carregado positivamente e os mesotrons podiam ser encontrados em versões positivas e negativas, "a probabilidade de captura para mésons negativos irá crescer, enquanto que para positivos ela será profundamente reduzida em decorrência da barreira de potencial coulombiano." (Ibid, p. 90, tradução nossa). Nos anos seguintes, um grupo de físico experimentais italianos (Conversi, Pancini \& Piccioni, 1947) publicou estudo comparando o número de decaimentos detectados por mésons positivos e negativos ao atravessarem camadas de ferro e carbono. Para a surpresa de Tomonaga e Araki, os resultados não apontaram para múons como uma entidade que interage fortemente com a matéria, fortalecendo ainda mais a ideia de que não se tratava da partícula proposta por Yukawa. As medidas 
de tempo de vida média também não eram animadoras, elas eram longas demais para uma partícula que deveria interagir fortemente com a matéria - o longo tempo indicava que se tratava de uma partícula que interagia fracamente.

Neste contexto, Taketani (1982) relata que sugeriu a Sakata uma separação nos decaimentos dos mésons, baseada em um ciclo de estágios. São eles o fenomenológico, o substancialista e o essencialista. Os fenômenos são materializados em substâncias, que podem ser interpretadas como partículas, que representam a essência daquilo que busca ser apreendido. A inspiração da corrente japonesa vem de correntes baseadas no materialismo dialético e tem como base a tríade tese-antítese presente na filosofia de Hegel. (TAKABAYASI, 1983). Sakata coloca os três estágios de pensamento em ação e defende que os resultados fenomenológicos não apresentavam discrepância com a teoria de Yukawa. A maneira substancialista de resolver o problema foi propor que a partícula que os experimentos estavam se referindo não era de fato a partícula de Yukawa, mas sim uma partícula que foi produzida como produto de um decaimento dela - propondo a existência de um segundo méson. Esta teoria de dois mésons também é formulada de forma paralela e independente por Charles Moller e Léon Rosenfeld (1939) e desenvolvida por Robert Marshak e Hans Bethe (1947).

A proposição de um segundo méson, aliada à confiança na teoria de Yukawa, fez com que a busca experimental se voltasse para aquela que seria a verdadeira partícula prevista pelo físico japonês. Com um tempo de meia vida cerca de 100 vezes menor que a do méson $\mu$, a partícula procurada passaria menos tempo percorrendo a atmosfera, portanto, encontrá-la seria uma tarefa tão difícil quanto buscar uma agulha num palheiro. Além do mais, como o múon era observado em altitudes relativamente baixas, o fato de ele ser produto do decaimento desta partícula procurada, indicava que ela estaria localizada em uma altitude ainda mais elevada.

A hipótese de que ela interagia fortemente com núcleos atômicos fortaleceu ainda a utilização de novas técnicas de deteccao, como a de emulsão nuclear, adotada por um grupo de físicos experimentais em Bristol, na Inglaterra. O físico brasileiro Cesar Lattes teve importante participação nestas observações. Com o aprimoramento da técnica, Lattes e Giuseppe Ochiallini (1947) conseguem produzir as primeiras imagens do méson $\pi$ após uma expedicao científica realizada ao topo do Pic-du-Midi, a quase 3 mil metros do nível do mar. A Figura 9 representa não apenas a detecção do méson $\pi$, como também demonstra o seu decaimento no meson $\mu$, como previsto pela teoria dos dois mésons desenvolvida por Sakata, Moller, Rosenfeld, Marshak e Bethe. No ano seguinte, Lattes consegue produzir mésons artificialmente usando o acelerador Cíclotron da Universidade de Berkelery, na California. A detecção do méson $\pi$ e o sucesso da teoria dos dois mésons, coroaram os esforços da escola teórica japonesa e colocaram um fim no paradoxo dos decaimentos dos mésons $\pi$ e $\mu$, que formaram o motor epistemológico da Fase das Interações. No entanto, a sensação de dever cumprido dura pouquíssimo tempo.

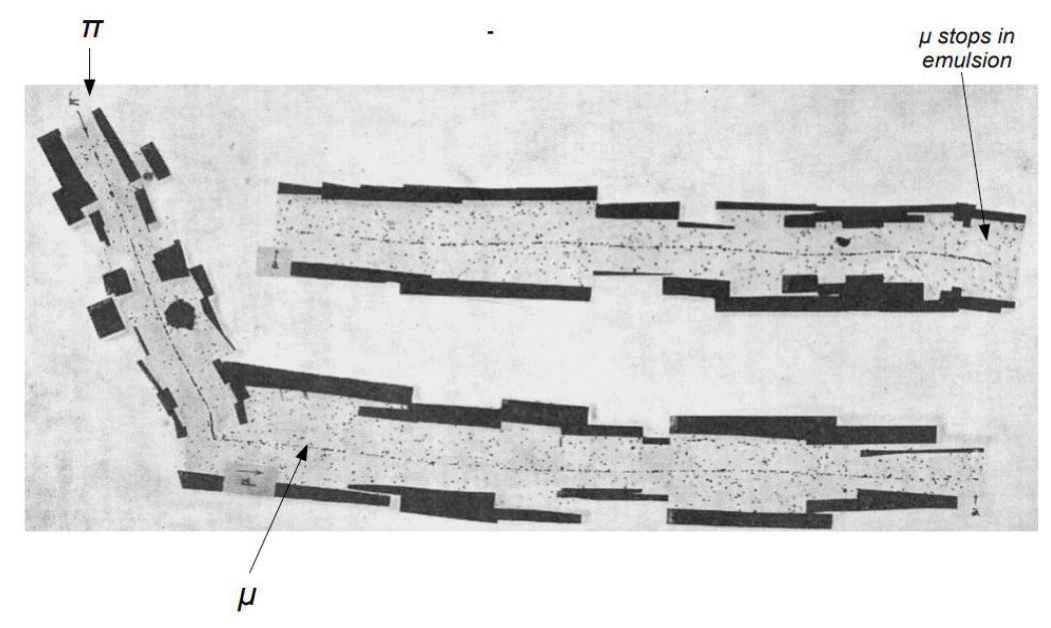

Figura 9 - Primeiras imagens evidenciando a existência dos dois mésons: $\pi$ e $\mu$. (Fonte: Lattes, 1947) 


\section{Fase das Simetrias e Conservações (1947-1964)}

\section{IV.1 0 mistério das V-particles e a explosão na produção de partículas}

Em um período de menos de 03 anos, a Física de Partículas caminhou de um ilusório sentimento de ordem, para uma verdadeira experiência de caos teórico e experimental. Uma época iniciada com uma massiva produção de dados obtidos com baixíssima precisão marcou um verdadeiro desespero teórico pela falta de estruturas explicativas para os novos fenômenos que não paravam de aparecer. É também um momento que marca os primeiros passos da internacionalização profunda da empreitada científica. Até meados da década de 1940, a Física de Partículas era discutida dentro dos departamentos ou em eventos regionais, reunindo pouco mais de dezenas de cientistas. Ao longo da década de 50, surgem eventos de amplitude mundial com periodicidade anual. Os encontros de Rochester, formalmente nomeado como Conferência Internacional da Física de Altas Energias (ICHEP), e as Conferências Internacionais de Raios Cósmicos (ICCR) existem até hoje e são marcos fundamentais para a pesquisa em Física de Altas Energias.

Em sua avaliação dos impactos científicos dos encontros de Rochester na década de 1950, Marshak (1989) relata que os dois primeiros encontros reuniram um pouco mais de 50 cientistas, e foram financiados com muito esforço por alguns pequenos setores industriais. Apesar da proposta, eles não tiveram um caráter verdadeiramente internacional, uma vez que regiões como a Europa e o Japão estavam em processo de reestruturação do período pós-guerra. Neste momento, os Estados Unidos já contavam com cinco aceleradores de partículas em funcionamento, com energias na faixa das centenas de $\mathrm{MeV}$. Esse fato sinalizava um ponto de inflexão do modo de estudo experimental das partículas elementares. O terceiro encontro de Rochester é considerado por Marshak como o primeiro de grande sucesso, contando com a presença de mais de 150 participantes. Em 1957, o sétimo encontro consegue reunir mais de 300 participantes de 24 nacionalidades. Os anos que seguiram deixaram claro que a colaboração internacional havia se tornado crucial para o desenvolvimento da Física de Altas Energias. Marshak aponta que "o número de participantes para os Rochester VIII, IX e X foi limitado a 300, demonstrando o crescimento explosivo do campo e do envolvimento de cientistas de trinta países". (1989, p.13, tradução nossa).

Sem deixar tempo para assimilar a confirmação dos mésons $\pi^{ \pm}$e $\mu^{ \pm}$, presente na publicação de Lattes, Occhialini e Cecil Powell em outubro de 1947, George Rochester e Clifford Butler publicam, em dezembro de 1947, evidências que apontam para existência daquilo que supuseram ser um conjunto de partículas ainda desconhecidas e que apresentam modos de decaimentos bastante peculiares:

Obtivemos [...] como parte de uma investigação da natureza das partículas penetrantes que ocorrem em chuveiros de raios cósmicos [...] duas fotografias contendo trajetórias bifurcadas de uma característica impressionante. Estas fotografias foram selecionadas dentro de cinco mil fotografias tiradas em um horário efetivo de operação de 1.500 horas. (Rochester \& Butler, 1947, p. 855, tradução nossa).

O conjunto de partículas identificadas eram eletricamente neutras, uma vez que não tinham suas trajetórias reveladas pelas câmaras de nuvens. Além do mais, sempre produziam um decaimento duplo numa trajetória bifurcada, apresentando um formato semelhante à letra $\mathrm{V}$, que os levou a denominá-las como $V$-Particles. Dentro de um conjunto de milhares de fotografias tiradas em milhares de horas de operação, foram encontrados apenas os dois eventos mostrados na Figura 10. Esses eventos poderiam sugerir tanto a existência de partículas raramente produzidas, quanto ser interpretados como traços de produções aleatórias, sem qualquer relação com a descoberta de novas partículas. 

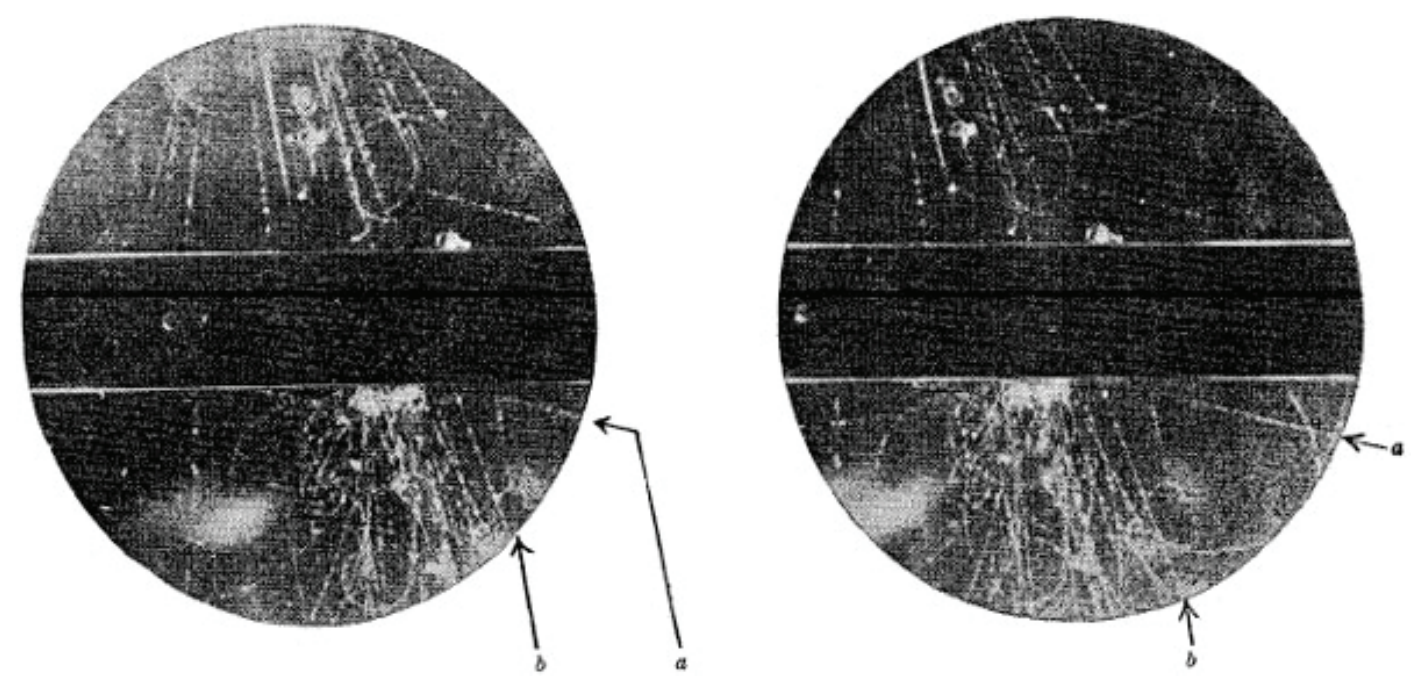

Figura 10 - Evidência da existência de um novo conjunto de partículas neutras que decaem em duas partículas a e b, formando uma trajetória bifurcada em forma de V. Rochester \& Butler, 1947

Em uma carta recebida e compartilhada por Rochester (1949 apud 1984, p.63, tradução nossa), Anderson afirma que os físicos poderiam ficar "contentes em ouvir que temos cerca de 30 casos de trajetórias bifurcadas similares como aquelas descritas em seu artigo na Nature cerca de dois anos atrás". Em 1950, Aaron Seriff, Robert Leghton \& Carl Anderson publicam a ocorrência de 34 eventos de trajetórias bifurcadas, identificadas em uma série de 11 mil fotografias, corroborando a hipótese que de fato tratava-se de um conjunto de partículas ainda desconhecidas.

Em 1949, o grupo de Bristol, responsável pela detecção do méson $\pi$, torna o cenário ainda mais estranho ao publicar evidências de um modo de decaimento mais complexo do que as $V$-particles - o decaimento de uma partícula em três píons carregados, denominado como méson- $\pi$, ilustrado na Figura 11.

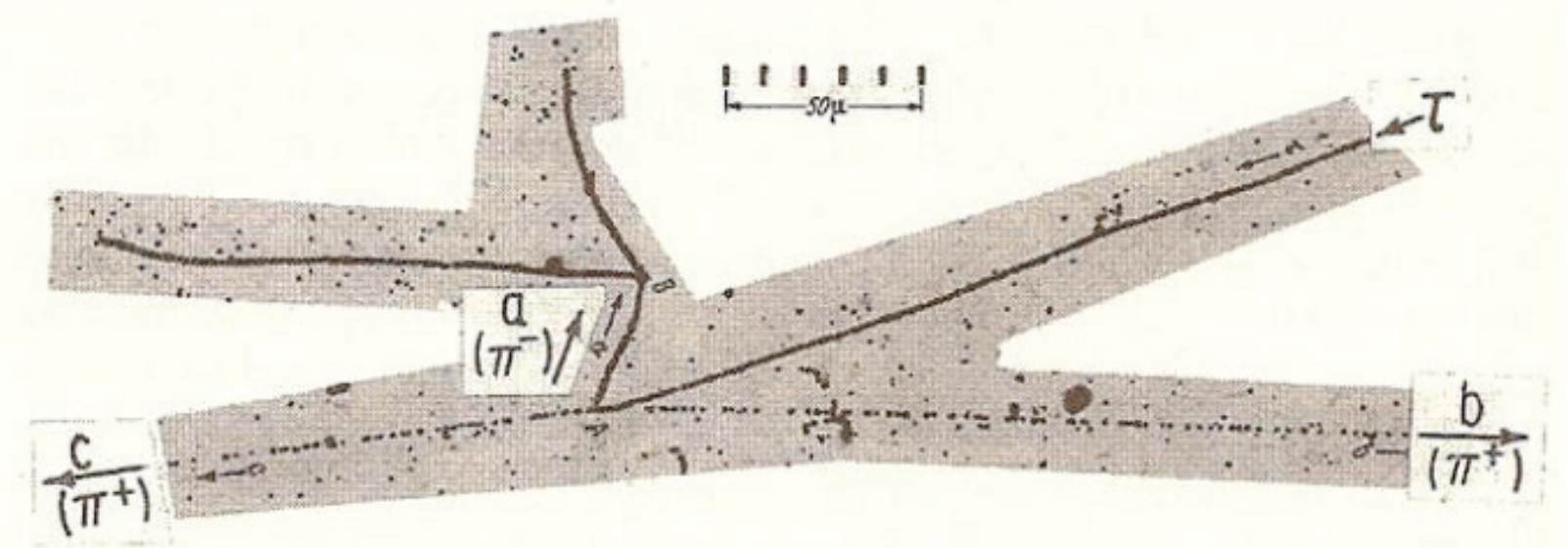

Figura 11 - Evidências de uma partícula de modo de decaimento triplo, denominado como méson- $\tau$, produzindo os píons carregados identificados pelas letras a, b e c. Fonte: Brown et al, 1949

Aquilo que no início de 1948 era conhecido simplesmente como $V$-particle começou a se multiplicar, surgindo nomenclaturas como $V_{0}, V_{0}^{1}, V_{0}^{2}, \tau, \mathrm{S}^{ \pm}$, assim como uma série de outras letras que estavam associadas aos formatos que as novas partículas apresentavam em seus modos de decaimento. É neste contexto 
que os Encontros de Rochester e as Conferências Internacionais de Raios Cósmicos exercem fundamental importância na organização, classificação e redefinição da nomenclatura destas partículas. Em 1952, naquele que foi considerado por Marshak o primeiro grande encontro de Rochester, um painel unicamente destinado a discussões sobre as $V$-particles apresenta um panorama nada animador, mostrado na Figura 12. (WRÓBLEWSKI, 2004)

\begin{tabular}{|c|c|c|c|c|}
\hline \multicolumn{5}{|c|}{$V$-particles and heavy mesons (December 1952) } \\
\hline Particle & lifetime (s) & $Q(\mathrm{MeV})$ & Mass $\left(m_{e}\right)$ & Spin \\
\hline $\begin{aligned} ? V_{1}^{ \pm} & \rightarrow p+\pi^{-} \\
& \rightarrow\left(n+\pi^{ \pm}\right) ?\end{aligned}$ & & & & half integral \\
\hline$V_{1}^{0} \rightarrow p+\pi^{-}$ & $3 \times 10^{-10}$ & $40 \pm 3$ & $2190 \pm 5$ & half integral \\
\hline$? S^{ \pm}, \chi^{ \pm}, V^{ \pm} \rightarrow \pi^{ \pm}+?$ & $10^{-8}-10^{-10}$ & & $900-1500$ & - \\
\hline$? S^{ \pm}, \kappa^{ \pm}, V^{ \pm} \rightarrow \mu^{ \pm}+(\gamma+\nu) ?$ & $10^{-8}-10^{-10}$ & & 1100 & integral \\
\hline$\tau^{ \pm} \rightarrow \pi^{ \pm}+\pi^{+}+\pi^{-}$ & $>10^{-9}$ & 75.8 & $977 \pm 6$ & integral \\
\hline$? V^{ \pm} \rightarrow \pi^{ \pm}+\pi^{0}+\pi^{0}$ & & & & integral \\
\hline $\begin{array}{l}\boldsymbol{V}_{2}^{\mathbf{0}} \rightarrow \pi^{+}+\pi^{-} \\
\rightarrow\left(\pi^{+}+\pi^{-}+?^{0}\right) ? \\
\rightarrow\left(\pi^{ \pm}+\tau^{ \pm} \text {or } \zeta^{0}\right) ?\end{array}$ & $2 \times 10^{-10}$ & & 950 & integral \\
\hline$? \zeta^{0} \rightarrow \pi^{+}+\pi^{-}$ & & & $500 ?$ & \\
\hline$? \zeta^{ \pm}$ & & & $500 ?$ & \\
\hline
\end{tabular}

Figura 12 - Quadro de partículas elementares discutidos no terceiro encontro anual de Rochester realizado em 1952. Fonte: Wróblewski, 2004

A Figura 12 deixa evidente que não havia absolutamente nada de conclusivo sobre as V-Particles em 1952. A primeira coluna demonstra uma falta de conhecimento completa nos modos de decaimento. As demais colunas contam com uma série de espaços sem valor experimental algum, assim como valores de precisão nada confiável, sendo muitos deles expressos apenas em termos da ordem de grandeza. Entre 1947 e 1954, muitas partículas foram identificadas nos experimentos com raios cósmicos e com o acelerador Cosmotron de Brookhaven. As V-Particles, originalmente identificadas por Rochester e Butler, foram renomeadas como Kaons ou mésons- $K$, classificadas num grupo de massa intermediária, maior que a dos píons e menor que a dos núcleons. As partículas nomeadas como lambda $(\Lambda)$, sigma $(\Sigma)$, e cascade $\Xi$ foram classificadas em um grupo denominado como híperons, caracterizado por partículas mais pesadas do que os núcleons. Todas estas partículas apresentavam tempos de vida média de ordens de grandeza variando entre $10^{-8}$ e $10^{-10} \mathrm{~s}$, $\mathrm{o}$ que era coerente com os tempos esperados para partículas produzidas via interação fraca.

Em 1952, no entanto, o acelerador cíclotron de Chicago forneceu evidência da existência de uma partícula que ficou conhecida como delta $(\Delta)$, que possuía tempos de decaimentos muitíssimos curtos, da ordem de $10^{-23} \mathrm{~s}$. A sugestão era de que sua produção ocorria via interação forte, produzindo em seu decaimento prótons e píons, entidades também interagentes via interação forte, que, por sua vez, decaiam em múons e elétrons, provocados pela interação fraca. Em 1961, o Cosmotron de Brookhaven apresentou evidências da existência de mais quatro partículas com tempos vida média da mesma ordem de $10^{-23} \mathrm{~s}$ : eta $(\eta)$, rho $(\rho)$, ômega $(\omega)$, e K-estrela $\left(K^{\star}\right)$. Em 1962, phi $(\phi)$ é adicionada a lista. Uma revisão de partículas publicadas no início da década de 60 sugeria a existência de um total de 30 partículas "elementares" (PICKERING 1984). 


\section{IV.2 Organizando as partículas estranhas na busca por simetrias e conservações}

De onde veio essa diversidade de partículas detectadas ao longo da década de 50 ? Por que em determinado momentos elas são produzidas via interação forte e, dentro de sua própria cadeia de decaimentos, a interação fraca passa a tomar as rédeas do fenômeno? Será que é possível prever os modos de decaimento de uma partícula? Descobrir por que sempre ela decai em um determinado conjunto de partículas e não em outros? Estes eram alguns questionamentos que colocaram os físicos teóricos contra a parede. Absolutamente nada do que havia sido desenvolvido do ponto de vista teórico até este momento da história, parecia ajudar na formulação de respostas a estes questionamentos.

O enfrentamento destes problemas exigiu a conjunção de esforços das escolas teóricas do ocidente e do oriente, que foram cruciais para resolver os problemas enfrentados na busca pelos mésons $\pi$ e $\mu$. Segundo Neeman (1971), as primeiras tentativas remontam os trabalhos de Pais (1952) e de Yoichiro Nambu et al (1951) nos Estados Unidos e no Japão. A abordagem consistia em buscar a existência de algum tipo de regra que permitisse separar os tipos de decaimentos que pudessem ocorrer daqueles que não poderiam. A Even-Odd Rule (Regra par-ímpar), como foi denominada por Abraham Pais, separava as partículas conhecidas no começo da década de 50 em dois grupos: as velhas e conhecidas (píons, nucleons, múons, elétrons e neutrinos); e as novas e estranhas ( $V$-Particles e mésons- $\tau$ ). Ao grupo das velhas e conhecidas, eram atribuídos números pares. Ao grupo das novas e estranhas, eram atribuídos números ímpares. De acordo com Pais (1952, p.666), para interações fortes e eletromagnéticas, "qualquer reação só é possível se as somas em ambos os lados forem ímpares ou pares simultaneamente"; se houver diferenças isso significa que ela é regida por interações fracas.

A regra permitia identificar os decaimentos possíveis de serem regidos por determinadas interações. Podemos tomar como exemplo o famoso decaimento identificado por Rochester \& Butler, representado como $\mathrm{V}_{0} \rightarrow \mathrm{p}+\pi$. Segunda a regra de seleção, ele tem em seu lado esquerdo ímpar (uma vez que consiste apenas de partículas estranhas), enquanto seu lado direito tem valor par (uma vez que consiste apenas de partículas conhecida). Isto implica que este não pode ser um decaimento regido por interações fortes e eletromagnéticas, e sim por interações fracas, o que estava de acordo com os tempos de vida média medido para ele. Ainda que de um caráter bastante primitivo, esta regra de seleção constrói a ideia de que a identificação de propriedades que se conservam em um decaimento são cruciais para julgar se as interações predominantes são fortes, eletromagnéticas ou fracas. Este movimento inspirou a busca por dois tipos de princípios de conservação: os gerais, obedecidos obrigatoriamente por todas as interações; e os restritos, obedecidos, por algum motivo, por algumas interações e não por outras. Segundo Pickering (1984), isto criou uma estrada de dois caminhos:

De um lado, eles aplicaram leis já conhecidas como definições para diferenciar o que era novo em termos das interações de partículas elementares; do outro, eles construíram novas leis de conservação empíricas, a fim de incorporar os dados experimentais na caracterização das interações fundamentais. (Pickering, 1984, p.50, tradução nossa)

Este caminho é trilhado independentemente por Gell-Mann (1956) nos Estados Unidos e Kazuhiko Nishijima (1955) no Japão. Antes de adentrar nos princípios de conservação gerais e restritos, é importante contextualizar como as partículas foram organizadas, uma vez que esta classificação será responsável pela formulação de diversos destes princípios. Ambos trabalhos resgatam a antiga proposta de Heisenberg de que prótons e nêutrons formam um dubleto, isto é, diferentes estados de uma mesma partícula denominada como nucleon. Eles buscam descrever as recentes descobertas em termos do formalismo de Isospin utilizado nesta proposta. O píon, por exemplo, forma um tripleto, tendo $\pi^{+}, \pi^{-}$e $\pi^{0}$ como os três estados de Isospin que o constitui. A Tabela 1 apresenta a forma como Gell-Mann e Nishijima organizaram os multipletos de Isospin das partículas conhecidas até o momento. Vale ressaltar que até $1956, \Sigma^{0}$ e $\Xi^{0}$ ainda não haviam sido detectados, no entanto, isso não os impediu de prevê-los antes mesmo de qualquer evidência experimental. Suas detecções são realizadas no ano seguinte no Cosmotron de Brookhaven pelo grupo de Jack Steinberger (Plano et al, 1957). 
Tabela 1 - Multipletos de Isospin propostos independentemente por Nishijima (1955) e Gell-Mann (1956)

\begin{tabular}{c|c} 
Multipleto & Estados de Isospin \\
\hline Tripleto $\pi$ & $\pi^{+}, \pi^{-}$e $\pi^{0}$ \\
\hline Tripleto $K$ & $\mathrm{~K}^{+}, \mathrm{K}^{-}$e $\mathrm{K}^{0}$ \\
\hline Dubleto nucleon & $\mathrm{p} \mathrm{e} \mathrm{n}$ \\
\hline Singleto $\Lambda$ & $\Lambda^{0}$ \\
\hline Tripleto $\Sigma$ & $\Sigma^{+}, \Sigma^{-}$e $\Sigma^{0}$ \\
\hline Dubleto $\Xi$ & $\Xi^{-}$e $\Xi^{0}$
\end{tabular}

Além da organização segundo os multipletos de isospin, Gell-Mann (1957) apresenta um panorama geral das partículas com informações bem estabelecidas ao final da década de 50 e as utiliza para fazer uma nova classificação. Na organização apresentada na Figura 13, é possível identificar, além do fóton, três grupos denominados pelo físico estadunidense como léptons, mésons e bárions, classificados segundo sua proximidade de massa. O primeiro grupo, denominado como léptons, seria formado pelas partículas leves $\mathrm{e}^{+}, \mathrm{e}^{-}, \mu^{+} \mathrm{e} \mu^{-}$. O segundo grupo, denominado como mésons, seria formado por partículas com massas intermediárias mais leves que os núcleons e mais pesadas que os píons, constituído por $\pi^{+}, \pi^{-}, \pi^{0}, K^{+}, K^{-}$e $\mathrm{K}^{0}$. O terceiro e último grupo, denominado como bárions, seria composto por partículas tão ou mais pesadas que o núcleons, incorporando nele $p, n, \Lambda^{0}, \Sigma^{0}, \Sigma^{ \pm}, \Xi^{0}, \Xi^{-}$.

Masses and Lifetimes of Elementary Particles

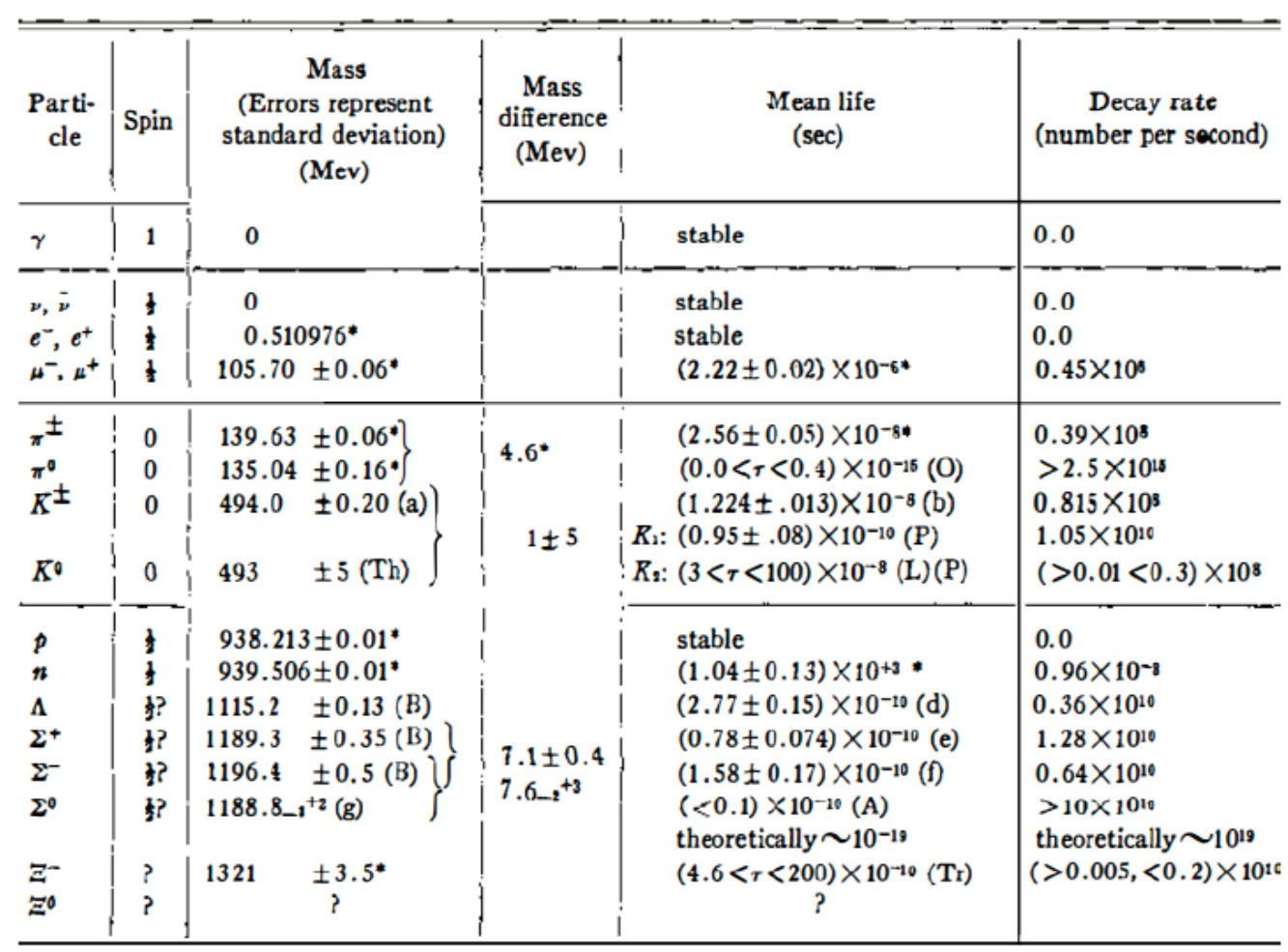

Figura 13 - Sistematização das partículas bem estabelecidas ao final da década de 50. Fonte: Gell-Mann, 1957

Por fim, inspirados na diferenciação entre partículas conhecidas e partículas estranhas, propostas na regra de seleção de Pais e Nambu et al, Gell-Mann e Nishijima introduzem um novo número quântico interno, denominado como estranheza. A princípio, este número seria utilizado como uma propriedade para 
diferenciar as partículas conhecidas das estranhas, descobertas e produzidas ao longo dos anos 1950. No entanto, o desenvolvimento do formalismo mostrou que esta foi uma conjectura mais poderosa do que a princípio se pensava. Com a explicitação da organização realizada em termos do Isospin, com a realização de uma classificação segundo a ordem de grandeza de suas massas e com a introdução da estranheza como um novo número quântico, temos condições de tratar os princípios de conservação geral e restrito assumidos pelos físicos teóricos na elaboração de seus trabalhos.

No que se refere a princípios de conservações gerais, dois são tomados como referência central: o princípio de conservação da energia e do momento angular. O princípio de conservação da energia, incorporando a conservação do momento linear em seu interior em consequência da relatividade especial, era um dos principais mecanismos utilizados para prever as energias necessárias para que determinadas partículas pudessem ser produzidas em aceleradores. De um lado, este princípio mostrava que era muito difícil imaginar que bárions secundários pudessem ser vistos como os produtos de decaimento de um bárion primário, enquanto que tornava fácil explicar a copiosa produção de méson em sua cadeia de decaimento. Também era muito utilizado para inferir a massa de partículas eletricamente neutras, que não tinham suas trajetórias explicitadas nas câmaras de nuvem, mas que podiam ser reconstruídas a partir de uma análise das partículas geradas em seus decaimentos. Já a conservação do momento angular tinha sua versão análoga à formulada nas primeiras versões da teoria quântica, aquela na qual o momento angular pode tomar apenas valores múltiplos inteiros de $\hbar \hbar$. Seu formalismo foi utilizado para descrever as transformações de isospin que provocavam a transição de estados entre as partículas. A conservação da carga elétrica também foi postulada como princípio geral, assim como a conservação de dois números quânticos interpretados de forma análoga a ela, como os números leptônico e bariônico. Todos estes princípios deveriam ser obedecidos por todas as interações, independente de sua natureza. Os princípios de conservação geral foram utilizados para estabilizar a discussão em termos daquilo que era permitido ou não. Já os princípios de conservação restritos apresentavam propostas de conservação que eram restritas às interações fortes ou eletromagnéticas e violadas pela presença das interações fracas. Eram os casos da conservação restrita da paridade, da estranheza e do isospin. Com este formalismo, Gell-Mann e Nishijima explicaram a ocorrência dos diversos decaimentos observados em experiências, antecipando a existência dos bárions $\Sigma^{0}$ e $\Xi^{0}$ e mostrando o poder preditivo da teoria.

\section{Um prelúdio ao Modelo Padrão da Física de Partículas Elementares}

A utilização dos princípios de conservação, apesar de colocar ordem na produção de partículas estranhas, apenas amenizou o problema. Pois, tratava-se de uma teoria meramente explicativa, sem muitas implicações sobre os mecanismos fundamentais que estavam por trás das violações provocadas nos princípios de conservação restritos. Mais do que explicar por que as interações fracas provocavam essas violações, era preciso construir uma teoria que fosse capaz de descrever simetrias exatas ou aproximadas dos sistemas envolvendo partículas elementares e a partir dela deduzir novos elementos. Acontece que até este momento, os teóricos imaginavam que este tipo de formalismo ainda não havia sido desenvolvido. O que ainda não se sabia é que seria preciso fazer a releitura de um tímido trabalho publicado na metade da década, que passou despercebido por grande parte da comunidade científica.

A elegante resolução que nos leva diretamente ao núcleo do que viria a ser o Modelo Padrão nas próximas décadas surge de uma não planejada união entre o físico chinês Chen Ning Yang e o estadunidense Robert Mills em um encontro no Brookhaven Laboratory em 1954. Suspeitando da conservação exata do isospin nas interações puramente nucleares, como seria elencado nas conservações restritas propostas por Gell-Mann e Nishijima, Yang e Mills apresentaram um exercício matemático onde descreveram, por meio da utilização da teoria de grupos, um mecanismo matemático capaz de manter o isospin simétrico, mesmo que seja aplicado sobre ele um determinado conjunto de transformações. Este foi o primeiro passo dado no que concerne à associação de simetrias à conservação das propriedades de um sistema, fazendo uso de um teorema proposto cerca de 30 anos antes pela matemática alemã Emmy Noether. 
O Teorema de Noether, materializado na Física pela proposta de Chen Ning Yang e Robert Mills, colocou em pauta o exercício de pensar na busca de simetrias como elementos cruciais na representação da conservação das propriedades de um sistema de partículas elementares. O passo além que ainda precisava ser dado, era adaptar o mecanismo de Yang-Mills para representar também quebras de simetrias, como era comumente visto pela ação que as interações fracas exerciam nos decaimentos. Isto representou uma reviravolta que ia dar origem ao Modelo Padrão da Física de Partículas Elementares, tendo como seu primeiro sucesso a formulação do quark como a entidade utilizada para explicar a diversidade de partículas estranhas descobertas ao longo da década 50.

A formulação do quark ocorre de forma independente nos Estados Unidos, com o trabalho de Gell-Mann (1964); no CERN, na Suíça, com o trabalho de George Zweig (1964) e em Israel, com o trabalho de Ne'emaan (1961). Apesar dos diferentes contextos, os trabalhos seguiram uma linha de pensamento muito semelhante, influenciada pela busca de simetrias que passou a ser considerado como o direcionamento epistemológico ao longo da década de 60. As simetrias se manifestam explicitamente num mecanismo que ficou historicamente conhecido como Eightfold Way, que buscava representar a organização dos multipletos de isospin e estranheza, propriedades conservadas nas interações fortes, em um esquema visualmente simétrico que organizava em grupos as partículas semelhantes. A Figura 14 apresenta o Eightfold Way representando octetos, nonetos e decupletos de mésons, à esquerda, e bárions, à direita.
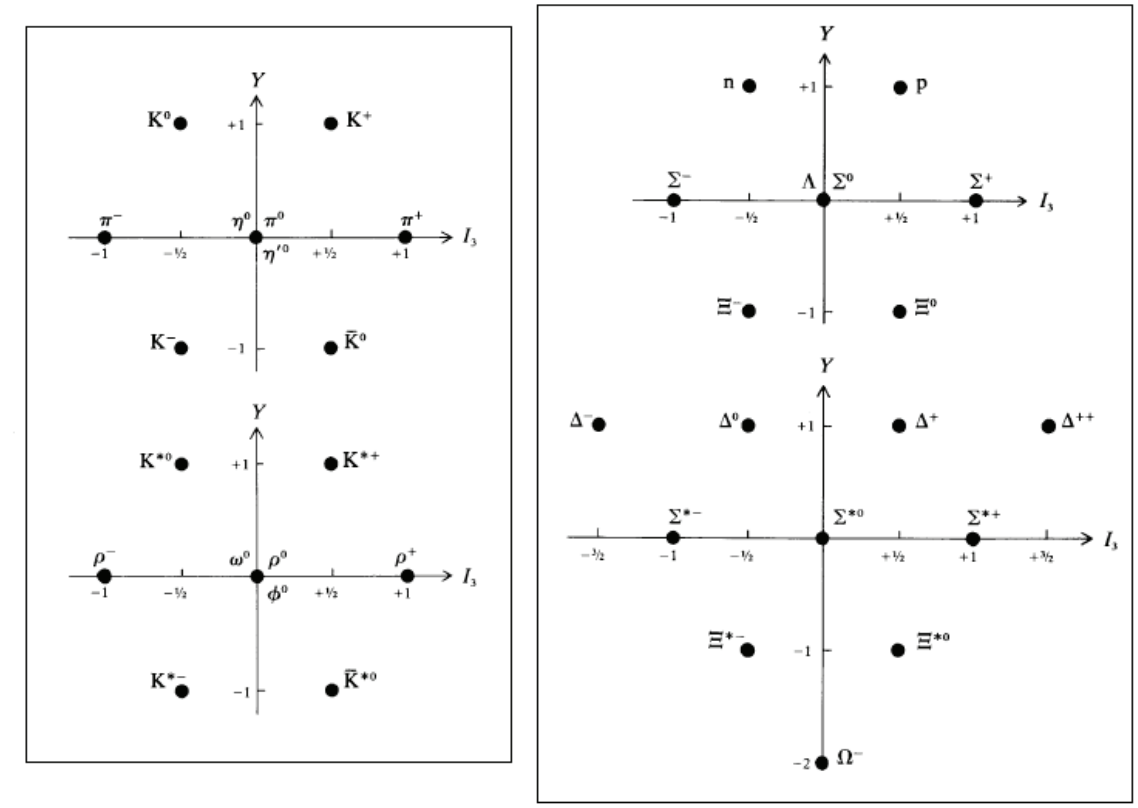

Figura 14 - Representação dos multipletos de isospin e estranheza no Eightfold Way. O quadro da esquerda representa a organização de mésons, enquanto que o da direita o de bárions. (PICKERING, 1984)

O Eightfold Way permitiu Gell-Mann fazer previsões de uma partícula ainda desconhecida, o $\Omega$, e permitiu Zweig descrever com maior detalhe os modos de decaimento do recente descoberto méson $\phi$. A possibilidade de organização de determinadas partículas no interior de determinados octetos, aliado à noção de que as interações fracas poderiam violar a conservação do isospin, provocando nele transformações em valores que poderiam fazer emergir as outras partículas do esquema, fizeram com que Zweig e Gell-Mann pensassem na construção de uma estrutura mais elementar.

As tentativas, no entanto, forneceram três entidades estruturais cujos números quânticos bariônico e de carga elétrica seriam fracionários, apresentando valores em módulo correspondentes a 1/3 ou 2/3. 
[...] ao assumirmos o número de bárion 1/3 para cada membro do tripleto, somos conduzidos a cargas elétricas não inteiras para $\left(\mathrm{p}_{0}, \mathrm{n}_{0}\right.$ e $\left.\Lambda_{0}\right)$. Chamaremos $\mathrm{p}_{0}, \mathrm{n}_{0}$ ou $\Lambda_{0}$ de "ace". [...] Trabalharemos com estes "aces" como unidades fundamentais no qual todos mésons e bárions são constituídos. (ZWEIG, 1964, p.4, tradução nossa)

A noção de três constituintes também aparece nos trabalhos de Ne'eman, por grande influência dos trabalhos de Sakata, que já havia proposto ainda na década de 50 a explicação da diversidade das partículas estranhas por uma tríade de entidades mais elementares (NE'EMAN, 1971). A noção de três unidades fundamentais foi capaz de explicar perfeitamente a constituição dos bárions e mésons, no entanto, a objetividade do pensamento ocidental os deixava sempre reticente à aceitação de novas entidades, tendo ainda que supor a existência de cargas elétricas fracionárias, o que pode ser percebido nos relatos de Gell-Mann e Zweig:

É razoavelmente possível que os "aces" sejam completamente ficcionais, providenciando uma forma meramente conveniente de expressar a quebra de simetria no Eightfold Way. Por outro lado, como veremos, uma busca experimental pelos "aces" poderia ser profundamente vantajosa. (ZWEIG, 1964, p.4, tradução nossa)

Eu não gostaria de chamar estes "quarks" confinados como reais porque gostaria de evitar dolorosas discussões com filósofos sobre a realidade destes objetos permanentemente confinados. (GELL-MANN, 1969, p.693, tradução nossa)

Sejam os aces de Zweig, os quarks de Gell-Mann ou o tripleto fundamental de Sakata incorporado nos pensamentos de Neeman, a aplicação de princípios de quebra de simetria foi fundamental para a formulação da tríade de entidades que absorveu toda a diversidade de mésons e bárions produzidos ao longo da década de 50. Este processo representa o sucesso de todo o projeto de investigação da natureza mais elementar da matéria, que foi o fio condutor da corrente epistemológica que percorreu a Física desde o início do século $\mathrm{XX}$. Com isto, a diversidade de partículas estranhas e conhecidas até este momento cede lugar a uma visão mais simples de constituição elementar da matéria: os quarks e os léptons, sendo os primeiros as entidades que constituiem os hádrons, partículas dotadas de estrutura interna, e os segundos elementos fundamentais para o entendimento das interações fracas. Um prelúdio para o Modelo Padrão começa a tomar forma com as características apresentadas na Figura 15.

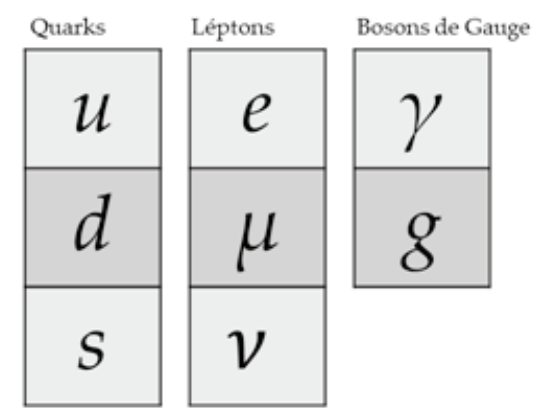

Figura 15 - O prelúdio ao Modelo Padrão da Física de Partículas com mésons e bárions constituídos internamente por quarks, tendo o glúon e o fóton como as partículas responsáveis por intermediar as interações fortes e eletromagnéticas. Fonte: Própria, 2019

Em um relato de sua trajetória como físico teórico, Gell-Mann esclarece que os princípios de simetria eram as peças que faltavam para completar o quebra-cabeça das partículas elementares: 
No momento em que tivemos sucesso na identificação dos padrões associados a simetrias [...] as teorias elegantes estavam apenas a alguns passos além. Estávamos, a partir do novo método teórico, encontrando as partículas por trás da cortina, como os bósons de gauge e os quarks. A razão mais profunda para isto é a de que as teorias que precisávamos eram na realidade teorias com dinâmicas baseadas nas simetrias. (GELL-MANN, 1994, p.5, tradução nossa)

Nos anos que seguiram, o mecanismo de Yang-Mills embasaram as primeiras teorias de Gauge que esclareceram diversos mistérios que circundavam as interações fortes:

Uma vez que reconhecemos o padrão de quarks subjacente aos hádrons e [...] entendemos que os quarks se organizam em 3 cores, com o grupo SU(3) de simetrias de cores aproximadamente conservado, não foi muito difícil caminhar da simetria à dinâmica dos hádrons. As interações fortes são descritas em termos de uma teoria de Gauge de Yang-Mills para quarks e gluons baseada no grupo de simetria de cor. (GELL-MANN, 1994, p.6, tradução nossa)

Assim como também se mostraram bem sucedidos na descrição das interações fracas, construindo uma teoria unificada com a teoria eletromagnética:

De forma similar, a interação fraca é descrita, juntamente com o eletromagnetismo, por uma teoria de Gauge de Yang-Mills para quebra de simetrias baseada nos grupos de Lie $\mathrm{SU}(2) \times \mathrm{U}(1)$ gerados pelas cargas fraca e eletromagnética. (GELL-MANN, 1994, p.6, tradução nossa)

Por fim, Gell-Mann ressalta que:

O Modelo Padrão consiste, em grande parte, de uma teoria construída nas simetrias exatas e aproximadas de um sistema de partículas elementares. (GELL-MANN, 1994, p.7, tradução nossa)

\section{Referências Bibliográficas}

ANDERSON, C. The Positive Electron. Phys. Rev. 43. 1933. 491.

ANDERSON, C. The Apparent Existence of Easily Deflectable Positives. Science. 76. 1932. 238.

ANDERSON, C. The production and properties of positrons. Nobel Lecture. Dez. 1936.

ANDERSON, C. Unraveling the Particle Content of the Cosmic Rays. In: SEKIDO, Y., HARRY E. Early history of cosmic ray studies: Personal reminiscences with old photographs. Vol. 118. Springer Science \& Business Media, 1982.

AUGER, P. Some aspects of French physics in the 1930s In: BROWN, L.M. \& HODDESON, L. The Birth of Particle Physics. Londres: Cambridge University Press. Agosto, 1983.

BAILY, C. Atomic modeling in the early 20th century: 1904-1913. Universidade de Colorado. 2008. Disponível em: $<$ http://philsci-archive.pitt.edu/4232/>. Acesso em 12/12/2019.

BROMBERG, J. The impact of the neutron: Bohr and Heisenberg. Historical Studies in the Physical Sciences. 3. 1971. 307-341.

BROWN, L. \& HODDESON, L. (Org.) The Birth of Particle Physics. Londres: Cambridge University Press. Agosto, 1983.

BROWN, L.M., DRESDEN, M. \& HODDESON, L. (Org.) Pions to Quarks: Particle Physics in the 1950s. Londres: Cambridge University Press. Novembro, 1989. 
BROWN, R. et al. Observations with electron-sensitive plates exposed to cosmic radiation. Nature. 1949. 47. BUSTAMANTE, M.C. A descoberta dos raios cósmicos ou o problema de ionização do ar atmosférico. Revista Brasileira de Ensino de Física, v. 35, n. 2. 2013.

CHADWICK, J. Possible Existence of a Neutron. Nature 129 (1932) 312.

CONVERSI, M et al. On the Disintegration of Negative Mesons Phys. Rev. 71. 1947. 209.

DIRAC, P. The Quantum Theory of the Emission and Absorption of Radiation

Proc. Roy. Soc. A114 (1927) 243;

DIRAC, P. The Quantum Theory of the Electron. Proc. Roy. Soc. A117. 1928. 610.

DIRAC, P. A Theory of Electrons and Protons. Proc. Roy. Soc. A126. 1930. 360.

FITAS, A., Mach: o positivismo e as reformulações da mecânica no séc. XIX. In: $3^{\circ}$ Encontro de Évora sobre História e Filosofia da Ciência. Évora. 1996. Atas. Disponível em: <http://home.uevora.pt/ afitas/AJSFitas-1998a-Mach.pdf> Acesso em: 22/12/2019.

FORTES, E.; Tijero, M. \& Pleitez, V. The discovery of the weak interactions's neutral currents. Revista Brasileira de Ensino de Física. 29. 3. 2007: 415-435.

GALISON, P. How experiments end. University of Chicago Press, 1987.

GALISON, P. Image and logic: A material culture of microphysics. University of Chicago Press, 1997.

GELL-MANN, M The Interpretation of the New Particles as Displaced Charge Multiplets Nuovo Cim. Suppl. 4. 1956. 848 .

GELL-MANN, M Rosenfeld, A.H.; Hyperons and Heavy Mesons (Systematics and Decay) Ann. Rev. Nucl. Sci. 7. 1957. 407.

GELL-MANN, M Schematic Model of Baryons and Mesons. Phys. Lett. 8. 1964. 214.

GELL-MANN, M. Indirect Approaches to Fundamental Theories, 1897-1899. In: NEWMAN, H. \& YPSILANTIS, T. History of original ideas and basic discoveries in particle physics. Enrice: NATO Scientific Affair Division. Agosto. 1994.

HAYAKAWA, S. The development of meson physics in Japan. In: BROWN, L.M. \& HODDESON, L. The Birth of Particle Physics. Londres: Cambridge University Press. Agosto, 1983.

HEISENBERG, W.; On the Structure of Atomic Nuclei. I. Z. Phys. 77. 1932. 1.

HODDESON, L., BROWN, L.M., RIORDAN, M. \& DRESDEN, M. (Org.) The Rise of the Standard Model: A History of Particle Physics from 1964 to 1979. Londres: Cambridge University Press. Novembro, 1997.

KAISER, D. Physics and Feynman's Diagrams: In the hands of a postwar generation, a tool intended to lead quantum electrodynamics out of a decades-long morass helped transform physics. American Scientist. 93. 2. 2005: 156-165.

BROWN, L., KONUMA, M., \& MAKI, Z. (Org.), Particle Physics in Japan, 1930-1950. Kyoto: Research Institute for Fundamental Physics. 1980.

LATTES, C., OCCHIALINI, G.P.S.; POWELL, C.F.; Observation on the Tracks of Slow Mesons in Photographic Emulsions. Nature. 160. 1947: 453.

MARSHAK, R. Scientific impact of the first decade of the Rochester conferences (1950-1960). In: BROWN, L.M. DRESDEN, M. \& HODDESON, L. Píons to Quarks: Particle Physics in the 1950s. Londres: Cambridge University Press. Novembro, 1989.

MARSHAK, R. e BETHE H. On the two-meson hypothesis. Physical Review. 72. 6. 1947: 506.

MARTINS R.A. Como Becquerel não descobriu a radioatividade. Cad. Cat. Ens. Fís., Florianópolis. 7. (Número Especial). 1990: 27-45.

MARTINS R.A. Descoberta dos Raios X: O Primeiro Comunicado de Rontgen. Revista Brasileira de Ensino de Física. 20. 4. 1998: 373.

MOLLER et al. Connexion between the Life-time of the Meson and the Beta-Decay of Light Elements. Nature 144. 1939: 629.

MOLLER, C, L. Rosenfeld. Theory of mesons and nuclear forces. Nature 143.3615 (1939): 241-242. 
NEDDERMEYER, S., ANDERSON, C. Note on the Nature of Cosmic-Ray Particles Phys. Rev. 51. $1937: 884$.

NISHIJIMA, K. Charge independence theory of V particles. Progress of Theoretical Physics. 13. 1955: $285-304$.

PAIS, A. Some remarks on the V-particles. Physical Review. 86. 1952: 663.

PICKERING, A. Constructing quarks: A sociological history of particle physics. University of Chicago Press, 1984.

PLANO, R., et al. Demonstration of the existence of the $\Sigma^{0}$ hyperon and a measurement of its mass. Nuovo Cimento. Italy. 1957.

ROCHESTER, G. Cosmic-ray cloud-chamber contributions to the discovery of the strange particles in the decade 1947-1957. In: BROWN, L.M. DRESDEN, M. \& HODDESON, L. Pions to Quarks: Particle Physics in the 1950s. Londres: Cambridge University Press. Novembro, 1989.

ROCHESTER, G. \& BUTLER, C. Evidence for the Existence of New Unstable Elementary Particles Nature. 160.1947. 855.

RUTHERFORD, E. The Magnetic and Electric Deviation of the easily absorbed Rays from Radium. Phil. Mag. 6. 1903. 177.

RUTHERFORD, E. The Scattering of $\alpha$ and $\beta$ Particles by Matter and the Structure of the Atom Phil. Mag. 21.1911. 669.

RUTHERFORD, E. The Structure of the Atom Nature Phil. Mag. 92. 1913. 423.

SCHWEBER, S. QED and the men who made it: Dyson, Feynman, Schwinger, and Tomonaga. Princeton University Press, 1994.

SCHWEBER, S. Nuclear forces: The Making of the Physicist Hans Bethe. I. Harvard University Press, 2012.

SERIFF, A. et al. Cloud-chamber observations of the new unstable cosmic-ray particles. Physical Review. 78. 1950: 290.

SKOBELTZYN, D. The early stage of cosmic:ray particle research. In: BROWN, L.M. \& HODDESON, L. The Birth of Particle Physics. Londres: Cambridge University Press. Agosto, 1983.

SKOBELZYN, D.V.; A New Type of Very Fast Beta Rays Z. Phys. 54. 1929: 686.

SMITH, G. J.J. Thompson and the Electron, 1897-1899. In: Buchwald, Jed Z., and Andrew Warwick, Histories of the electron: the birth of microphysics. MIT Press, 2004.

STREET, J.C.; STEVENSON, E.G.; New Evidence for the Existence of a Particle of Mass Intermediate Between the Proton and Electron. Phys. Rev. 52. 1937: 1003.

TAKABAYASI, T. Some characteristic aspects of early elementar particle theory in Japan. In: BROWN, L.M. \& HODDESON, L. The Birth of Particle Physics. Londres: Cambridge University Press. Agosto, 1983.

TAKETANI, M. Theoretical Study of Cosmic Rays in Japan. In: SEKIDO, Y., HARRY E. Early history of cosmic ray studies: Personal reminiscences with old photographs. Vol. 118. Springer Science \& Business Media, 1982.

TOMONAGA, S \& ARAKI, G. Effect of the nuclear Coulomb field on the capture of slow mesons. Physical Review. 58. 1940: 90.

WEINBERG, Steven. The search for unity: Notes for a history of quantum field theory. Daedalus. 1977: 17-35.

WEISSKOPF, V. Growing up with field theory: the development of quantum electrodynamics. In: BROWN, L.M. \& HODDESON, L. The Birth of Particle Physics. Londres: Cambridge University Press. Agosto, 1983.

WILSON, F. Fermi’s theory of beta decay. American Journal of Physics. 36. 1968: 1150-1160.

WRÓBLEWSKI, A. Hypernuclei (and strange particles) - How it all began? Acta Physica Polonica B. 35. 2004.

NE'EMAN, Y. Concrete Versus Abstract Theoretical Models. In: ELKANA, Y (Org.) Interaction Between Science and Philosophy. Humanities Press. 1974: pp. 1-25.

YAGI, E. The Development of Nagaoka’s Saturnian Atomic Model II (1904-05). Japanese Studies in the History of Science. 11. 1972: 73-89.

YANG, C. \& MILLS, R; Conservation of Isotopic Spin and Isotopic Gauge Invariance; Phys. Rev. 96. 1954. 191.

ZWEIG G. An SU(3) Model for Strong Interaction Symmetry and its Breaking. CERN-TH-401. 1. 1964. 